\title{
Context-Sensitive Spell-Out and Adjacency
}

\author{
Peter Ackema and Ad Neeleman
}

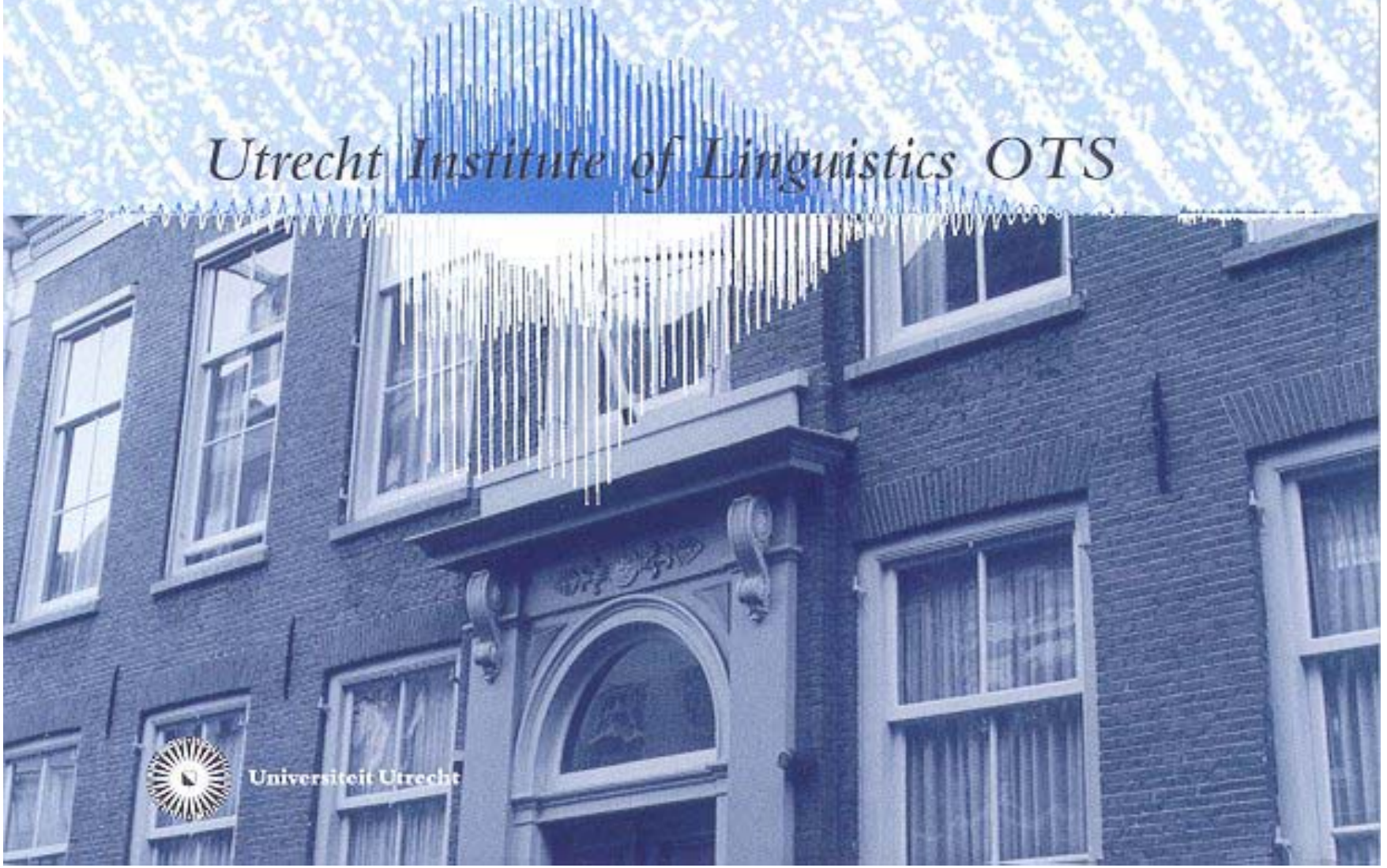




\title{
CONTEXT-SENSITIVE SPELL-OUT AND AdJACENCY*
}

\author{
PETER ACKEMA AND AD NEELEMAN
}

24 JULY 2001

\author{
(Ackema) \\ Utrecht University \\ UiL OTS \\ Trans 10 \\ 3512 JK Utrecht \\ The Netherlands \\ ackema@let.uu.nl \\ (Neeleman) \\ Department of Phonetics and Linguistics \\ UCL \\ Gower Street \\ London \\ WC1E 6BT \\ United Kingdom \\ ad@ling.ucl.ac.uk
}

\footnotetext{
* Material from this paper was presented as part of the MA Syntax Seminars at UCL in 1998 and 2001, at Utrecht University and at the Fourth International LEHIA Workshop at the University of the Basque Country, Vitoria. We would like to thank the audiences for helpful input. We would further like to thank Hans van de Koot, Fred Weerman and Moira Yip for commenting on earlier drafts.
} 


\section{CONTEXT-SENSITIVE SPELL-OUT AND ADJACENCY}

\section{INTRODUCTION}

Various apparently syntactic phenomena are conditioned by adjacency. Perhaps the best-known example is case assignment in English: a DP dependent on the verb for case must be adjacent to it, whereas the distribution of case-less elements, such as PP complements, is not restricted in the same way (Stowell 1981):

(1) a. John read (*slowly) the book

b. John read (slowly) to his children

Since syntax deals with hierarchical rather than linear relationships, adjacency is a concept alien to it. Hence, adjacency requirements which are syntactic at first blush must be reanalyzed in one of two ways. The first is to develop a hierarchical account which happens to have the adjacency effect as a by-product. This is essentially the approach Chomsky (1995) adopts for the data in (1). The alternative is to analyze the adjacency requirement in terms of the phonology-syntax interface, which by its very nature deals with matters of linear order and therefore provides a natural locus for adjacency conditions.

We do not address the issue of case adjacency in this paper. Instead, we show that for a range of apparently syntactic rules conditioned by adjacency a PF approach is more attractive, both conceptually and empirically. The data we discuss involve agreement weakening under subject-verb inversion in Dutch (section 3) and Standard Arabic (section 5); Middle Dutch object cliticization (section 6); pro-drop in Celtic (section 7), Old French (section 8) and Arabic (section 9); Dutch complementizer substitution (section 10); and Germanic complementizer agreement (section 11). Before we turn to these phenomena, however, we should make explicit our assumptions about the syntax-phonology mapping and the kind of rules we will employ.

\section{THE PROPOSAL}

As is well known, phonological representations are not necessarily isomorphic to syntactic representations, and phonological and syntactic primitives are members of disjoint sets. A simple example illustrating this, borrowed from Jackendoff (1997:26), is given in (2). In syntax, a big house is a DP that consists of a determiner and a complex NP complement. In phonology, it consists of two phonological words, the first of which is formed by the determiner and the adjective. So, both constituency and labels differ.

$$
\begin{array}{ll}
\text { a. } & {\left[{ }_{D P} \text { a }\left[{ }_{\mathrm{NP}}\left[{ }_{\mathrm{AP}} \text { big }\right] \text { house }\right]\right]} \\
\text { b. } & {\left[{ }_{\varphi}[\omega\right.}
\end{array}
$$

It is implausible that (2a) and (2b) are derivationally connected. Familiar derivations operate under a condition of informational monotonicity: they can add, but not destroy or change structural relations and labels on nodes. If no derivation connects (2a) and (2b), syntax and phonology must be autonomous generative systems, each creating structures governed by independent wellformedness principles. 
This hypothesis in turn entails that a set of PF mapping rules must be formulated in order to account for regularities in the association of syntactic and phonological representations. In general, such rules state that certain elements in the syntactic representation correspond to certain elements in the phonological representation. One subset of mapping rules associates boundaries of syntactic categories with boundaries of phonological categories (see Selkirk 1986, McCarthy \& Prince 1995, Truckenbrodt 1995, amongst others). For example, in the languages we discuss in this paper the right edges of syntactic XPs typically correspond to the right edges of prosodic phrases (other languages may align left edges of syntactic and prosodic phrases). We can write the mapping rule stating this as in (3), where $\Pi$ is a mapping function. According to the rule, a right XP-bracket in syntax is mapped onto a right $\varphi$-bracket in phonology.

$$
\Pi(<\text { right edge, } \mathrm{XP}>)=<\text { right edge, } \varphi>
$$

Thus, the (partial) syntactic structure in (4a) corresponds to the (partial) prosodic structure in (4b). (Here and below $\varphi$ boundaries are indicated by braces).

(4) a. [[A friend [of Mary's]] [showed [some pictures] [to John]]]

b. $\quad$ A friend of Mary's \{showed some pictures\} \{to John\}

A second type of mapping rule must be adopted for lexical items. In GB theory and some variants of minimalism, all information contained in a lexical item is inserted or merged in syntax. That is, a syntactic terminal does not only contain syntactic information, but also information which is irrelevant to syntax, such as its phonological form. As will be clear, this view is at odds with models that assume a strict separation of syntax and phonology. The alternative, advocated by Jackendoff 1997 amongst others, claims that lexical items are minimal idiosyncratic mapping rules which relate syntactic terminals to their phonological realization. The syntactic feature bundle $\left[\mathrm{D}, 3^{\mathrm{RD}}\right.$ PERSON, SINGULAR, FEMININE, ACCUSATIVE], for example, corresponds to the phonological form $/ \mathrm{her} /$ in English, as stated by the rule in (5). (Here and below we sometimes mark syntactic material by uppercase and phonological material by lowercase placed between forward slashes).

$$
\Pi\left(\left[\mathrm{D}, 3^{\mathrm{RD}}, \mathrm{SG}, \mathrm{FEM}, \mathrm{ACC}\right]\right)=/ \text { her } /
$$

Interestingly, there is some interaction between lexical spell-out rules and the mapping rules that associate syntactic and phonological domains. Some spell-out rules appear to be context-sensitive (see for instance Halle \& Marantz's (1993:123 ff.) discussion on 'conditioned allomorphy'). What this means is that in addition to simple spell-out rules of the type in (6a) (exemplified by (5)), mappings of the type in (6b) must be allowed (where $\mathrm{D}$ is a local phonological domain).

$$
\begin{array}{ll}
\text { a. } & \Pi(\mathrm{A})=/ \mathrm{a} / \\
\text { b. } & \operatorname{In}[\mathrm{D} \Pi(\mathrm{A}), \Pi(\mathrm{B})], \\
& \Pi(\mathrm{A}) \rightarrow / \mathrm{a}^{\prime} /
\end{array}
$$

The rule in (6b) states that a syntactic feature bundle A receives a special spell-out if a feature bundle 
$\mathrm{B}$ is realized within the same phonological domain D. Notice that the rules in (6a) and (6b) stand in an elsewhere relation, so that application of the more specific rule in $(6 \mathrm{~b})$ is obligatory if its structural description is met.

In this paper we concentrate on rules of the type in (6b) whose structural description mentions the prosodic phrase as the domain of application. Suppose that in some language there are general spell-out rules for a head $\mathrm{H}$ and a phrase $\mathrm{XP}$, as well as a specific spell-out rule of the type in (6b). This rule may state that XP receives a special spell-out (/xp'/ rather than /xp/) if realized in the same prosodic phrase as $/ \mathrm{h} /$, the phonological counterpart of $\mathrm{H}$. If the language forms phonological phrases in accordance with (3), the specific spell-out rule can only apply if XP immediately follows $\mathrm{H}$ (see $\left.\left(7 \mathrm{a}, \mathrm{a}^{\prime}\right)\right)$. In all other contexts, $\mathrm{H}$ and XP are not realized in the same prosodic phrase, so that the general spell-out rule for XP applies (see (7b-c)).
a. $\quad \mathrm{HXP}$
a'. $\left\{/ \mathrm{h} / / \mathrm{xp}^{\prime} /\right\}$
b. $\quad \mathrm{XP} \mathrm{H}$
b'. $\{/ \mathrm{xp} /\}\{/ \mathrm{h} / \ldots$
c. $\quad \mathrm{YPP}$ XP
c'. $\{/ \mathrm{h} / / \mathrm{yp} /\}\{/ \mathrm{xp} /\}$

By their very nature, lexical spell-out rules are language-specific. Languages simply do not spell-out the same feature bundles in the same way. If this is true of spell-out rules in general, it must hold of context-sensitive spell-out rules as well. However, although the content of such rules is languagespecific, there are general restrictions on their format and application, such as the following.

Many context-sensitive spell-out rules are rules of reduction. In some cases, the reduction involves the phonological status of the element affected by the rule. Thus, a pronoun may be spelled out as a phonological word according to the general rule, but as a phonologically dependent category (a clitic or affix) in a particular context. In other cases, reduction may involve syntactic features. Suppose that the target of the rule $(\mathrm{A}$ in $(6 \mathrm{~b}))$ and the element mentioned in the rule's structural description (B in (6b)) share one or more phi-features. The special spell-out rule may then suppress the phonological realization of one of A's features. This state of affairs is schematized below:

$$
\begin{aligned}
& \text { a. } \quad \Pi\left(\left[\begin{array}{lllll}
\mathrm{A}_{\mathrm{A}} & \ldots & \mathrm{F}_{1} & \ldots .
\end{array}\right]\right)=/ \mathrm{a} / \\
& \text { b. } \quad \Pi\left(\left[{ }_{\mathrm{A}} \ldots \mathrm{F}_{1}, \mathrm{~F}_{2} \ldots\right]\right)=/ \mathrm{a}^{\prime} / \\
& \text { c. } \quad \operatorname{In}\left[{ }_{D} \Pi\left(\left[_{A} \ldots F_{1}, F_{2} \ldots\right]\right), \Pi\left(\left[{ }_{B} \ldots F_{2} \ldots\right]\right)\right] \text {, } \\
& \Pi\left(\left[_{A} \ldots F_{1}, F_{2} \ldots\right]\right) \rightarrow \Pi\left(\left[\left[_{A} \ldots F_{1} \ldots\right]\right)\right.
\end{aligned}
$$

(8a) and (8b) are rules which determine the realization of some element A dependent on its featural content, but independent of the environment in which it finds itself. (8c) is a context-sensitive spellout rule which suppresses the effects of a feature $\mathrm{F}_{2}$ in the realization of $\mathrm{A}$ when an identical feature is present on another element in the same local domain.

Suppression of the phonological effects of syntactic features is subject to recoverability. First, as assumed above, a feature can only fail to be spelled out in the context of an identical feature. Let us call this feature $-\mathrm{F}_{2}$ on $\mathrm{B}$ in $(8 \mathrm{c})$ - the triggering feature. Second, in contexts where 
(8c) applies, $\mathrm{B}$ may not itself undergo a PF reduction rule which suppresses the effects of $\mathrm{F}_{2}$ for its phonological realization, even if such a rule applies in other contexts in the language. Thus, the following conditions hold:

\section{Recoverability}

a. Suppression of a feature requires a triggering feature

b. A triggering feature cannot be suppressed

If the prosodic phrase counts as a local domain for rules of reduction, we may expect it to count as a local domain for other PF rules as well. In particular, it is generally assumed that certain features are licensed in the proximity of an element carrying identical features (this is the concept underlying checking theory; see Chomsky 1995). Proximity is usually defined syntactically, notably as specifierhead agreement. We propose, however, that certain types of checking require phonological proximity. That is, the local domain D mentioned in the schema for feature-checking in (10) can be specified as the prosodic phrase:

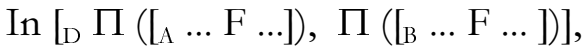

$$
\begin{aligned}
& \mathrm{F} \text { is checked }
\end{aligned}
$$

When checking takes place in prosodic phrases, the constituent whose feature is checked must immediately follow the checking head. As in the case of rules of reduction, the structural description of the rule otherwise fails to be met (see $\left(7 \mathrm{a}, \mathrm{a}^{\prime}\right)$ ). This approach hence makes available a natural account of adjacency conditions on checking relations (such as case adjacency). Phonological checking will be the topic of the penultimate section. We start by discussing various feature-based reduction rules.

\section{DutCH AgREEMENT WEAKENING}

The Dutch verbal agreement paradigm has a curious property: the conjugation of the second person singular depends on the position of the agreeing verb with respect to the subject. As will be clear from the regular present tense endings in (11), the second person singular is usually marked by $-t$.

$\begin{array}{ll}\text { ik loop } & \text { wij loop-en } \\ \text { I walk } & \text { we walk-pl } \\ \text { jij loop-t } & \text { jullie loop-en } \\ \text { you walk-2sg } & \text { you walk-pl } \\ \text { hij loop-t } & \text { zij loop-en } \\ \text { he walk-3sg } & \text { they walk-pl }\end{array}$

Dutch has verb-second in root clauses, a fact traditionally analyzed in terms of $\mathrm{V}$-to- $\mathrm{C}$ raising in root environments followed by the fronting of an arbitrary constituent to spec-CP (see Den Besten 1983). Thus, when a constituent other than the subject is fronted, the net effect is subject-verb inversion: 
(12) a. [CP dat [Marie vandaag naar het vioolconcert van Sibelius luistert]] that Mary today to the violin-concerto by Sibelius listens

b. [CP Marie [C luistert [ $\mathrm{t}_{\mathrm{DP}}$ vandaag naar het vioolconcert van Sibelius $\mathrm{t}_{\mathrm{V}}$ ] Mary listen-3sg today to the violin-concerto by Sibelius

c. $\quad\left[\mathrm{CP}\right.$ Vandaag [C luistert [Marie $\mathrm{t}_{\mathrm{Advp}}$ naar het vioolconcert van Sibelius $\left.\left.\left.\mathrm{t}_{\mathrm{V}}\right]\right]\right]$ today listen-3sg Mary to the violin-concerto by Sibelius

Although agreement is not in general sensitive to this type of inversion, the - $t$ ending that marks the second person singular is omitted in inversion structures. This results in a form homophonous to the first person singular (that is, a form without an overt ending):
a. [CP dat [jij dagelijks met een hondje over straat loopt] that you daily with a doggy in the street walk-2sg
b. [CP Jij [C loopt [ $\mathrm{t}_{\mathrm{DP}}$ dagelijks met een hondje over straat $\left.\left.\left.\mathrm{t}_{\mathrm{V}}\right]\right]\right]$ you walk-2sg daily with a doggy in the street
c. $\quad\left[{ }_{C P}\right.$ Dagelijks [C loop [jij $\mathrm{t}_{\mathrm{AdvP}}$ met een hondje over straat $\left.\left.\left.\mathrm{t}_{\mathrm{V}}\right]\right]\right]$ daily walk you with a doggy in the street

When there is subject-verb inversion, the subject DP is realized in the same prosodic phrase as the verb. This is illustrated in (14c), the prosodic structure corresponding to (13c). In contrast, in (14b) the subject's right XP-boundary induces a $\varphi$-boundary between its realization and the realization of the verb. In the embedded clause in (14a) even more $\varphi$-boundaries intervene.
a. $\quad\{$ dat jiij $\{$ dagelijks $\}$ \{met een hondje\} \{over straat\} \{loopt that you daily with a doggy in the street walk-2sg
b. $\quad\{\mathrm{Jij}\}$ \{loopt dagelijks\} \{met een hondje\} \{over straat\} you walk-2sg daily with a doggy in the street
c. $\quad$ Dagelijks\} \{loop jij\} \{met een hondje\} \{over straat\} daily walk you with a doggy in the street

Consequently, $(14 a, b)$ require that subject agreement is spelled out in the regular way. However, if there were a specific spell-out rule of the type in $(6 \mathrm{~b})$ with the domain specified as the prosodic phrase, it would apply in (14c). The omission of the inflectional ending in (13c)-(14c) can indeed be attributed to such a rule. To make this clear, let us consider the feature system underlying the (Dutch) person/number paradigm. Here we will partially follow proposals by Kerstens (1993) and Harley \& Ritter (1998).

We assume the following rules for verbal agreement in the Dutch present tense. The features [PRT], [ADD] and [PLR] are unitary and stand for participant (in the speech act), addressee and plural, respectively. Which rule applies is dictated by the elsewhere condition. (Note that the apparent syncretism of second and third person singular is a historical accident; various dialects of Dutch still have a distinct second person - st ending.) 


$$
\begin{array}{ll}
\text { a. } & \Pi([\mathrm{V}, \text { PRT }])=/ \mathrm{v} / \\
\text { b. } & \Pi([\mathrm{V}, \text { PRT, ADD }])=/ \mathrm{v} /-/ \mathrm{t} / \\
\text { c. } & \Pi([\mathrm{V}, \text { PLR }])=/ \mathrm{v} /-/ \mathrm{en} / \\
\text { d. } & \Pi([\mathrm{V}])=/ \mathrm{v} /-/ \mathrm{t} /
\end{array}
$$

The agreement alternation illustrated in (13)-(14) can now be captured by the following contextsensitive spell-out rule:

$$
\begin{aligned}
& \text { Dutch Agreement Weakening } \\
& \text { In }[\varphi(\Pi([\mathrm{V}, \mathrm{PRT}, \mathrm{ADD}]), \Pi([\mathrm{D}, \mathrm{PRT}, \mathrm{ADD}])], \\
& \Pi([\mathrm{V}, \mathrm{PRT}, \mathrm{ADD}]) \rightarrow \Pi([\mathrm{V}, \mathrm{PRT}])
\end{aligned}
$$

This rule states that the verb's [ADD] feature is not realized if the verb is in the same prosodic domain as a second person DP. Consequently, the verb appears in its [PRT] form, that is, as the first person singular.

If a context-sensitive spell-out rule is responsible for the alternation in (14), it is predicted that a verb agreeing with a [PRT, ADD] subject can only appear in its [PRT] form if no XP intervenes between the two. Intervention of an XP would have the consequence that the verb and the subject are no longer realized in the same prosodic phrase, in contrast to what the structural description of the rule demands. Indeed, fronting a constituent to a position between a verb in $\mathrm{C}$ and the subject is generally possible $\left(\left(17 \mathrm{a}, \mathrm{a}^{\prime}\right)\right)$, except if the used form of the verb depends on the special rule in (16) (see Paardekooper 1961 and E. Hoekstra 1996 for related discussion and observations). ${ }^{1}$
a. $\quad\{$ Volgens mij\} \{gaat zelfs hij\} \{op de heetste dag van 't jaar\} \{naar het park\} according-to me go-3sg even he on the hottest day of the year to the park
a'. $\quad$ Volgens mij\} \{gaat op de heetste dag van 't jaar\} \{zelfs hij\} \{naar het park\} according-to me go-3sg on the hottest day of the year even he to the park
b. $\quad$ Volgens mij\} \{ga zelfs jii\} \{op de heetste dag van 't jaar\} \{naar het park\} according-to me go even you on the hottest day of the year to the park
b'. $\quad *\{$ Volgens mii\} \{ga op de heetste dag van 't jaar\} \{zelfs jii\} \{naar het park according-to me go on the hottest day of the year even you to the park.

When the special rule cannot apply, the general rule should. Thus, (17b') should improve if the $-t$ ending expressing [Prt, Add] is used. Indeed, (18) is considerably better than (17b').

$$
\begin{aligned}
& \text { ? }\{\text { Volgens mij\} \{gaat op de heetste dag van ' } \mathrm{t} \text { jaar\} \{zelfs jii\} \{naar het park\} } \\
& \text { according-to me go-2sg on the hottest day of the year even you to the park }
\end{aligned}
$$

The example is not perfect, but this is presumably due to a parsing difficulty rather than the grammar. Examples with a fronted constituent between verb and inverted subject are relatively rare. Hence, if a speaker of Dutch encounters the string in (19), where XP is not the subject, he or she will expect a third person singular subject to follow (in general such expectations facilitate efficient parsing). Hence, the continuation in (18) creates a garden-path effect. 
We may note that the effect gets weaker with repetition or if more material intervenes between verb and subject, as expected if it is psycholinguistic in nature. Real mismatches in agreement, as in (20) for instance, are much worse than (18) to begin with, and do not improve either with repetition of the type of example or if the distance between verb and subject is enlarged.

$$
\begin{aligned}
& *\{\text { Volgens mij\} \{gaan op de heetste dag van 't jaar\} \{zelfs jii\} \{naar het park\} } \\
& \text { according-to me go-pl on the hottest day of the year even you(sg) to the park }
\end{aligned}
$$

So far, we have assumed the traditional analysis of verb second, which treats the phenomenon as uniform $\mathrm{V}$-to-C raising. In other words, we assume that subject-initial and non-subject-initial root clauses differ with respect to the position of the subject (which is in spec-CP or spec-IP, respectively), rather than with respect to the position of the verb. Travis (1984) and Zwart (1997a) advocate an alternative view, according to which it is the position of the verb that is different in the two cases. When there is subject-verb inversion the verb is still assumed to be in C, but in subjectinitial structures the verb is assumed to be in I (which is taken to precede its complement in Dutch). So, on this analysis the subject always occupies the same position, spec-IP:

(21) a. [IP Marie [I, luistert [vandaag naar het vioolconcert van Sibelius $\left.t_{\mathrm{V}}\right]$ ]] Mary listen-3sg today to the violin-concerto by Sibelius

b. [CP Vandaag [C luistert [IP Marie [ [ $\mathrm{t}_{\mathrm{V}} \mathrm{t}_{\mathrm{AdvP}}$ naar het vioolconcert van Sibelius $\left.\left.\left.\mathrm{t}_{\mathrm{V}}\right]\right]\right]$ today listen-3sg Mary to the violin-concerto by Sibelius

As pointed out by Zwart, this analysis also allows a straightforward account of the agreement alternation under discussion. On this account, the spell-out rules are sensitive to the syntactic position occupied by the verb. If $\mathrm{V}$ is in $\mathrm{I}$, second person singular is realized as - $t$, if $\mathrm{V}$ is in $\mathrm{C}$, this ending is omitted. Using the features introduced above, this can be expressed by the rules in (22).

$$
\begin{array}{ll}
\text { a. } & \Pi([\mathrm{V}, \text { Prt, Add }])=/ \mathrm{v} /-/ \mathrm{t} \\
\mathrm{b.} & \text { Dutch Agreement Weakening } \\
& \text { In }[\mathrm{c}[\mathrm{V}, \text { Prt, Add }]], \\
& \Pi([\mathrm{V}, \text { Prt, Add }])=/ \mathrm{v} /
\end{array}
$$

At first sight, there does not seem to be much difference between Zwart's syntactic conditioning of the spell-out rules and the prosodic conditioning proposed here, except perhaps that the rule in (16), in contrast to that in (22b), links agreement weakening to the proximity of an agreeing element and therefore provides some intuitively plausible motivation for its existence. More importantly, however, the syntactic analysis faces a number of empirical set-backs (see also Weerman 1989, Vikner \& Schwartz 1996 and Williams 1998). These fall into two classes. The first concerns problems with the analysis of verb second that it is based on; the second, problems with the assumption that the syntactic position of the verb determines whether agreement is weakened or not. 
As the example in (23a) illustrates, elements can be fronted to the left edge of IP in embedded clauses in Dutch. If subject-initial clauses were bare IPs, we would expect similar fronting to be allowed, which would lead to verb third order. This is impossible, however, as (23b) shows. In contrast, the analysis in terms of uniform $\mathrm{V}$-to-C raising does account for the strict obeyance of the verb second constraint in root clauses.

(23) a. [CP dat [IP op de heetste dag van 't jaar [IP zelfs hij [I, I [VP naar het park gaat]]]]] that on the hottest day of the year even he to the park go-3igg

b. $\quad{ }^{*}{ }_{\text {IP }}$ Op de heetste dag van 't jaar [IP zelfs hij [r' gaat [vP naar het park $\left.\left.\left.\left.\mathrm{t}_{\mathrm{V}}\right]\right]\right]\right]$ on the hottest day of the year even he goes to the park

A second problem is related to the fact that Travis's and Zwart's analyses incorporate the traditional analysis of Verb Second as a subcase. It is still possible to raise the verb to $\mathrm{C}$ and move an arbitrary constituent to spec-CP. There is nothing in the theory that rules out derivations in which this arbitrary constituent is the subject, for example if the subject is focussed or a contrastive topic. Thus, subject-initial clauses are predicted to be ambiguous between a CP and an IP analysis. However, in that case subject-initial clauses should optionally show agreement weakening, in accordance with the rule in (22b). This is not the case:
a. [IP Jij [i, loopt [dagelijks met een hondje over straat $\left.\left.\left.\mathrm{t}_{\mathrm{V}}\right]\right]\right]$ you walk-2sg daily with a doggy in the street
b. $\quad{ }^{*}\left[{ }_{C P}\right]$ Jij [C, loop [IP $t_{D P} t_{V}$ [dagelijks met een hondje over straat $\left.\left.\left.\left.t_{V}\right]\right]\right]\right]$ you walk daily with a doggy in the street

Finally, the adjacency effects in (17) and (18) remain a mystery if agreement weakening is conditioned by the syntactic position of the verb only. In both (17b) and (17b'), the verb is in C, the only difference being that in (17b') a constituent intervenes between verb and subject. That such intervention blocks application of the special spell-out rule suggests that the syntactic position of the verb is irrelevant. What the rule states instead is that the verb and the subject must be in the same prosodic domain.

\section{Some Clarifications about the Syntac-Phonology Mapping}

In the previous section, we have illustrated in what way prosodic phrasing conditions contextsensitive spell-out and what advantages our approach has over syntactic alternatives, at least in the case of Dutch second person agreement. Before we extend our approach to other empirical domains, we would like to make some clarifications with regards to the properties we assume the PF interface to have.

To begin with, it is well known that many phonological processes which take place within prosodic phrases are sensitive to pausing, speech rate effects, etc. This suggests that prosodic structures can be adjusted on the basis of performance factors, a conclusion which in turn seems to predict that context-sensitive spell-out should be affected by performance in a similar way. This is not correct for Dutch second-person agreement, nor for any of the phenomena discussed below. 
However, arguably a distinction should be made between processes that apply at the PF interface and processes which happen post-PF, in phonology proper. The mappings we discuss in this paper by necessity take place at the interface. They relate the syntax to an abstract prosodic representation. This abstract representation in turn underlies a surface form derived by operations that apply beyond the interface and are triggered by conditions of weight distribution, etc. A similar distinction between interface operations and operations that take place beyond the interface is standard in the literature on LF.

This assumption entails is that there should be other domains in which effects of prosodic structure can be observed without there being any phonology in the traditional (post-PF) sense. This prediction is borne out, we believe, by work in sentence processing. Fodor 2001 and others show that in silent reading tasks subjects assign an abstract prosodic structure to the strings they are parsing. It seems reasonable to assume that this prosodic structure exists independently of traditional phonological information. No sounds are produced or perceived in silent reading.

The second issue we wish to clarify concerns the inventory of PF mapping rules. Although the analyses we present all rely on the condition in (3), it goes without saying that there are various other rules of alignment that determine how syntactic and prosodic structures can be paired. For example, the left edge of finite CPs typically coincides with the left edge of an intonational phrase. Given that prosodic phrases must be properly contained in intonational phrases, the syntactic structure in (25a) is not mapped onto the prosodic structure in (25b), as one would expect on the basis of (3), but rather onto (25b') (where angled brackets indicate intonational phrases).

$$
\begin{array}{ll}
\text { a. } & [\text { [John }][\text { believes [CP that [Mary] [loves [Bill] }]]]] \\
\text { b. } & *\{\text { John }\} \text { believes that Mary }\} \text { loves Bill }\} \\
\text { b'. } & <\{\text { John }\} \text { believes }\}><\text { that Mary }\{\text { loves Bill }\}>
\end{array}
$$

The example illustrates that futher alignments co-determine the environments in which contextsensitive spell-out may take place. (25b) would allow special spell-out rules that assign the subject of a finite complement an alternative realization in the presence of certain matrix verbs, a phenomenon which is not attested in the languages we discuss. The representation in (25b'), on the other hand, places the matrix verb and the embedded subject in different prosodic phrases and thus blocks context-sensitive spell-out of the embedded subject. For reasons of presentation we will henceforth abstract away from alignments other than those forced by (3), but this should not be taken as a claim that (3) exhaustively characterizes the syntax-phonology mapping.

The final clarification we would like to make concerns spell-out operations which apparently involve more than one syntactic constituent and which nevertheless do not adhere to the generalizations we suggest in this paper. The type of process we have in mind is illustrated by the Dutch examples below, in which a specifier and a head are combined into a phonological word. This may seem surprising, given that the rule in (3) has the effect that in the initial prosodic structure, specifiers and heads are placed in different prosodic phrases.

$$
\begin{aligned}
& \text { a. Dat is leuk } \\
& \text { That is nice }
\end{aligned}
$$


b. $\quad[\omega$ Da's] leuk

That-is nice

Phenomena of this type, we believe, should not be handled at the PF interface, but rather in phonology proper. They do not involve the special spell-out of an element conditioned by the initial prosodic structure, but rather an adjustment of the initial prosodic structure on the basis of an independent phonological realization of one of the items involved.

In the case at hand, the crucial observation is due to Hoeksema (1985), who shows that the formation of da's cannot be due to a rule of final $t$ deletion, given that in the same context the demonstrative dit 'this' does not give rise to $* d i$ 's. We therefore propose that $d a$ is stored in the lexicon as a variant of $d a t$, while dit lacks the variant ${ }^{*} d i$. The reduced version of the demonstrative is phonologically best characterized as a pro-clitic. Its insertion therefore forces a restructuring of the prosodic structure to give $\left[\omega\right.$ da is], which in turn gives rise to [ $\left[_{\omega} d a s\right]$ under pressure of general phonological conditions.

There is independent evidence for the existence of $d a$. The reduced form of the demonstrative also occurs in examples like (27) and (28). The former is phonologically different from (26) in that the verb in $\mathrm{C}$ has an initial consonant; the latter is syntactically different: it shows that the distribution of the reduced demonstrative is not restricted to spec-CP. In neither context is a shortened variant of dit allowed.
a. Dat mag niet
That may not
'That is not allowed'
b. [ $\quad$ dammag] niet
That-may not

(28) a. Jan vraagt of je dat nu eindelijk gedaan hebt John asks whether you that finally done have

b. Jan vraagt of je $\left[_{\omega}\right.$ dannu] eindelijk gedaan hebt John asks whether you that-finally done have

On this analysis, the example in (26) is not a case of context-sensitive spell-out, and hence it does not present a counterexample to the claim that such spell-out is conditioned by (3).

Let us now return to our main line of argumentation.

\section{ARABIC AgreEMENT WEAKENING}

In Dutch, agreement weakening is restricted to the second person singular (it targets the [Add] feature). Of course, similar rules may affect other features in other languages. In fact, a contextsensitive reduction rule targeting the $[\mathrm{Plr}]$ feature can account for a well-known agreement alternation in Modern Standard Arabic. ${ }^{2}$ The analysis we propose echoes work by Benmamoun (1997, 2000), although it is developed differently.

The basic observation is as follows. Standard Arabic is a VSO language which allows for the fronting of various constituents. If the subject is fronted, yielding SVO order, there is full agreement 
in person, number and gender (strong agreement). If the subject remains in situ, however, agreement is restricted to person and gender only (weak agreement). This is illustrated in (29) (from Fassi Fehri 1993:32).
a. daxal-at n-nisaa?-u makaatib-a-hunna
entered-FEM the-women-NOM office-PLR-ACC-their-FEM
a'. *daxal-na n-nisaa?-u makaatib-a-hunna
entered-FEM-PLR the-women-NOM office-PLR-ACC-their-FEM
b. n-nisaa?-u daxal-na makaatib-a-hunna
the-women-NOM entered-FEM-PLR office-PLR-ACC-their-FEM
b'. *n-nisaa?-u daxal-at makaatib-a-hunna
the-women-NOM entered-FEM office-PLR-ACC-their-FEM

There is one exception to this general pattern: there is obligatory full agreement with postverbal pronominal subjects. We abstract away from this here, but return to it in section 9 .

Given that Arabic distinguishes plural from singular agreement, spell-out rules of the type in (30) must be assumed (which actually stand for a set of spell-out rules, as indicated by the parentheses). Note that the rule for the singular is less specific than the one for the plural, so that if SVO order obtains and the subject is plural, the rule for the singular is blocked. The more specific rule must be used in this case. The question, then, is why this should be different in VSO order.

$$
\begin{array}{ll}
\text { a. } & \Pi([\mathrm{V}, \mathrm{PLR},(\mathrm{ADD}),(\mathrm{PRT}),(\mathrm{GEN})])=/ \mathrm{v} \text {-affix } / \\
\text { b. } & \Pi([\mathrm{V},(\mathrm{ADD}),(\mathrm{PRT}),(\mathrm{GEN})]=/ \mathrm{v} \text {-affix'/ }
\end{array}
$$

Let us assume that VSO word order is derived by fronting of the verb to some functional head $\mathrm{F}$ (cf. (31a)), while SVO order is derived by movement of the subject to spec-FP (cf. (31b)); see Sproat 1985, McCloskey 1997 and others, also for discussion of the nature of F, something irrelevant to our present purposes). As will be clear from the previous sections, the two structures differ in whether or not the verb is realized in the same prosodic phrase as the subject. Given the mapping principle in (3) this is only the case in the VSO order, as indicated in (31a', b’).

$$
\begin{aligned}
& \text { a. [FP [F V } \left.\left[\text { [IP SUBJECT } t_{\mathrm{V}}\left[{ }_{\mathrm{VP}} \mathrm{t}_{\mathrm{V}} \text { OBJECT }\right]\right]\right] \\
& \text { a'. } \quad\{/ \mathrm{v} / / \text { subject } /\}\{\text { /object/ }\} \\
& \text { b. [FP SUBJECT [F V] [ip } \left.\mathrm{t}_{\text {SUBJECT }} \mathrm{t}_{\mathrm{V}}\left[{ }_{\mathrm{Vvp}} \mathrm{t}_{\mathrm{V}} \text { OBJECT }\right]\right] \\
& \text { b'. } \quad\{/ \text { subject } /\}\{/ \mathrm{v} / / \text { object } /\}
\end{aligned}
$$

As a consequence, an agreement weakening rule of the type discussed in section 3 can affect ( $\left.31 \mathrm{a}^{\prime}\right)$, but not (31b'). The rule in question is formulated in (32). Note that, although the spell-out rule for plural agreement is more specific than the one for singular agreement, the rule in (32) is in turn more specific than the one for the plural. Hence, it takes priority where its structural description is met. 


$$
\begin{aligned}
& \text { Arabic Agreement Weakening } \\
& \text { In }\left[{ }_{\varphi} \Pi([\mathrm{V}, \mathrm{PLR}, \ldots]), \Pi([\mathrm{D}, \mathrm{PLR}, \ldots])\right], \\
& \Pi([\mathrm{V}, \mathrm{PLR}, \ldots]) \rightarrow \Pi([\mathrm{V}, \ldots])
\end{aligned}
$$

The analysis can be straightforwardly extended to a set of data discussed by Benmamoun (1997), concerning structures containing both an auxiliary verb and a main verb. In such structures, the subject can either be placed between the two verbs or in sentence-initial position. Agreement covaries with order: only verbs that follow the subject show strong agreement, see (33).
a. kaanat T-Taalibaat-u ya-?kul-na
be-PAST-3sg-FEM the-students-FEM-PLR-NOM 3-eat-FEM-PLR
'The students were eating'
b. T-Taalibaat-u kun-a ya-?kul-na
the-students-FEM-PLR-NOM be-PAST-3-FEM-PLR 3-eat-FEM-PLR
b'. *kun-a T-Taalibaat-u ya-?kul-na
be-PAST-3-FEM-PLR the-students-FEM-PLR-NOM 3-eat-FEM-PLR

We assume that the auxiliary is generated in an Aux position (perhaps T) and moved to $\mathrm{F}$, as in (34a). The optional subject movement encountered above then results in (34b). As the corresponding prosodic structures show, agreement weakening can apply to the auxiliary in (34a'), but not in (34b'). Neither structure allows for weakening the main verb's agreement.

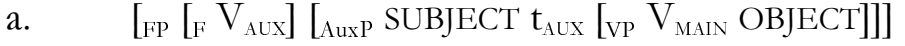

$$
\begin{aligned}
& \text { a'. } \quad\left\{/ \mathrm{v}_{\mathrm{AUX}} / / \text { subject } /\right\}\left\{/ \mathrm{v}_{\text {MaIN }} / / \text { object } /\right\} \\
& \text { b. [FP SUBJECT [F } \mathrm{V}_{\text {AUX }} \text { [ [Auxp } \mathrm{t}_{\text {SUBjeCt }} \mathrm{t}_{\text {Aux }}\left[\mathrm{vp} \mathrm{V}_{\text {MaIN }}\right. \text { OBJECT]]] } \\
& \text { b'. } \quad\{/ \text { subject } /\}\left\{/ \mathrm{v}_{\text {AUX }} / / \mathrm{v}_{\text {MAIN }} / / \text { object } /\right\}
\end{aligned}
$$

So, the Arabic data can be analyzed as involving agreement weakening in prosodic phrases. An alternative, syntactic, analysis might be that strong agreement obtains when the subject and the verb are in a specifier-head configuration in overt syntax. Analyses based on such an assumption have indeed been proposed by Huybregts (1991) and Fassi Fehri (1993), among others. Let us consider such proposals, slightly rephrased here in current minimalist terms.

Suppose that strong agreement in Standard Arabic requires the verb and its subject to be in a specifier-head configuration in overt syntax. Then, the data in (33) can be analyzed as follows. In (33b), both the main verb and the auxiliary have strong agreement, which implies the subject must move from a specifier position in which it checks the main verb's features (say spec- $\mathrm{FP}_{2}$ ) to spec-FP, where it checks the auxiliary's features, as in (35a). In (33a), only the main verb has strong agreement, with the consequence that movement of the subject to spec-FP is procrastinated (or takes the form of feature movement). ${ }^{3}$ This is illustrated in $(35 b) .{ }^{4}$

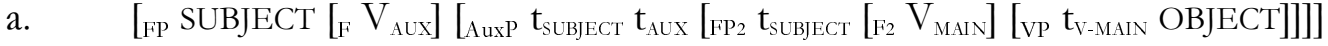

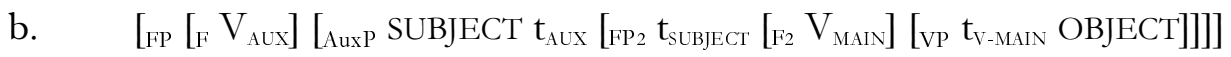


With this in mind, let us return to the examples that do not involve an auxiliary. Assuming the same structures as before, the SVO and VSO orders must be analyzed as in (36a) and (36b) respectively. However, if the trace of the subject can check strong agreement against the main verb in $\mathrm{FP}_{2}$ in structures with an auxiliary as in (35), there is no reason why it cannot do so in (36b). In other words, there is no reason why strong agreement should be incompatible with VSO order, as in fact it is. (N.B. Possibly the AuxP is not present in (36), so that the spec-head relation between the overt subject and the verb's trace would hold in $\mathrm{FP}_{2}$. This does not affect the argument.)

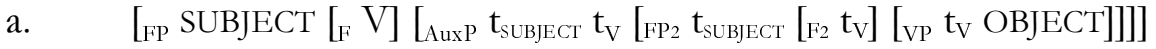

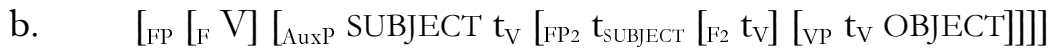

The only difference between (35) and (36b) is that in the latter structure agreement is checked by the verb's trace, rather than by the head of the verbal chain. This means the syntactic account can be salvaged by assuming that only overt verbs can check strong agreement in Arabic. However, traces can be considered full copies of their antecedents (Chomsky 1995), which means that there is no reason to expect that they could not participate in checking relations. In fact, verbal traces can perfectly well participate in regular syntactic checking. For example, agreeing verbs in verb second languages can move to $\mathrm{C}$ across the subject without this leading to any problems. ${ }^{5}$

\section{Middle Dutch Pronoun Weakening}

Like present-day Dutch (see section 3), Middle Dutch has verb second in root contexts. As opposed to modern Dutch, it has a set of object clitics, in addition to the strong and weak pronouns that exist in both languages. These clitics occupy a fixed position in the clause: they immediately follow the head in $\mathrm{C}$, with which they form a phonological word. Thus, in main clauses they attach to the fronted verb in $\mathrm{C}$, whereas in embedded clauses they attach to the complementizer (examples from Van der Horst 1981 and Weerman 1987):

(37) a. Nu moete-ne onse vrouwe bewaren

now must-him our lady save

b. $\quad$ Soe troest-se de hope vander goetheit Gods

in-this-way consoles-her the hope of-the goodness god-GEN

c. datt-en God niet en spaert

that-him God not NEG saves

d. dat-se onse here troest

that-her our lord consoles

We argue that this type of cliticization involves another special spell-out rule of the type in (6b), with the domain specified as the prosodic phrase.

According to one view, clitics are nominal elements which are base-generated on the verb and which absorb the verb's internal $\Theta$-role and accusative features (see for instance Miller \& Sag 1997, Monachesi 1999 and references mentioned there). For Middle Dutch object clitics, however, such an analysis cannot work. ${ }^{6}$ The data in $(37 \mathrm{c}, \mathrm{d})$ show that the clitic attaches to $\mathrm{C}$ even if this position is occupied by a complementizer rather than the verb. Since the clitic is the internal 
argument of the verb all the same, it seems that for this type of cliticization it must be assumed that the clitic starts out as the verb's complement and moves to its surface position.

This ties in with another popular view of cliticization, according to which the phenomenon is an instance of head movement. Note, however, that an analysis of Middle Dutch object clitics according to which they move from their base position directly to C violates Travis' (1984) head movement constraint, as illustrated in (38). (We assume that clitics are D heads, see Corver \& Delfitto 1993, amongst others).

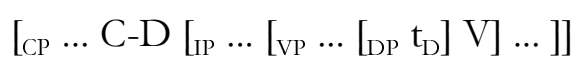

This means that cliticization to C must be a two-step process. As Cardinaletti \& Roberts (1991) propose for analogous cases, the object DP first undergoes phrasal movement to the left periphery of IP (thus avoiding a violation of the head movement constraint), after which its head cliticizes to C. An important argument for the conjectured phrasal movement is that full pronouns can undergo it as well. They, too, can be found in a position to the left of the subject (cf. (39a,b)), as well as in a position lower in the tree (cf. (39c,d)) (Middle Dutch examples from Van Gestel et al. 1992:112,150).

(39) a. Doe so bat heme Lanceloet then so asked him Lancelot

'Then Lancelot asked him thus'

b. dat mi die crancheit sal doen dolen

that me the illness will do wander

'that the illness will make me err'

c. Soe moetti [...] mine mesdaet mi vergheven

so must-he my crime me forgive

'So he must forgive me my crime'

d. In hebbe niet mi gheset daertoe

I-NEG have not me applied there-to

'I have not applied myself to that'

Cardinaletti \& Roberts 1991 view cliticization in the cases under discussion as an instance of head movement. The D-head of the pronominal DP incorporates into the host. The complete derivation is given in (36), where the first step of DP movement consists of adjunction to IP (Cardinaletti \& Roberts analyze it as movement to the specifier position of a functional projection, but this does not affect the argumentation here).

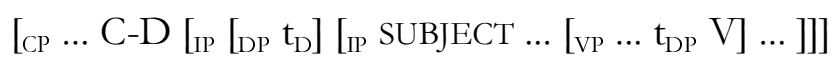

Although the head movement constraint is now satisfied, the head movement in (40) violates another well-established condition on movement. Huang's (1982) condition on extraction domains bans movement from adjuncts and specifiers (see Baker 1988 for arguments that this condition indeed restricts head-to-head movement as well). ${ }^{7}$ Moreover, if object cliticization is achieved 
through movement, it remains unclear why it invariably takes the form of encliticization rather than procliticization in Middle Dutch. As we now argue, a prosodic account of the actual cliticization step fares better in these respects.

The DP movement to the left edge of IP, which was shown above to be independently available for object pronouns in Middle Dutch, creates a context in which a pronoun finds itself in the same prosodic phrase as a head, namely the complementizer or the fronted verb in C. This contrasts with what is the case when the pronoun remains in its base position or is shifted to a position following the subject. ${ }^{8}$ The crucial structures are given in (41), where DP represents the pronoun.

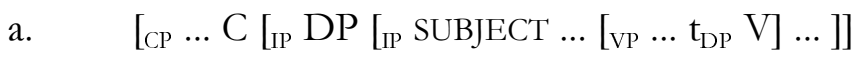

$$
\begin{aligned}
& \text { a'. } \quad\{\ldots\}\{/ \mathrm{c} / / \mathrm{dp} /\}\{/ \text { subject } /\}\{\ldots\}\{/ \mathrm{V} /\}
\end{aligned}
$$

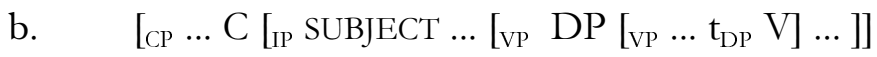

$$
\begin{aligned}
& \text { b'. } \quad\{\ldots\}\{/ \mathrm{c} / / \text { subject } /\}\{/ \mathrm{dp} /\}\{\ldots\}\{/ \mathrm{v} /\}
\end{aligned}
$$

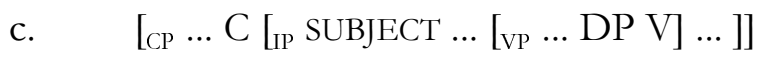

$$
\begin{aligned}
& \text { c'. } \quad\{\ldots\}\{/ \mathrm{c} / / \text { subject } /\}\{\ldots\}\{/ \mathrm{dp} /\}\{/ \mathrm{v} /\}
\end{aligned}
$$

In (41a'), but not in (41b') or (41c'), a special spell-out rule can apply. The realization rules for Middle Dutch pronouns then have the general format in (42), in line with what we have assumed so far. (There is, of course, a pair of specific rules for each combination of pronoun and associated clitic. Note that '[C]' in the weakening rule's structural description might be generalized to ' $[\mathrm{H}]$ ', which represents an arbitrary head, but we abstract away from that possibility here).

$$
\begin{array}{ll}
\text { a. } & \Pi([\mathrm{D},(\mathrm{PRT}),(\mathrm{ADD}), \ldots])=/ \mathrm{d}_{\omega} / \\
\mathrm{b} . & \text { Middle Dutch Pronoun Weakening } \\
& \text { In }[\varphi([\mathrm{C}]), \Pi([\mathrm{D},(\mathrm{PRT}),(\mathrm{ADD}), \ldots]), \\
& \Pi([\mathrm{D},(\mathrm{PRT}),(\text { ADD }), \ldots]) \rightarrow / \mathrm{d}_{\sigma} /
\end{array}
$$

The general rule in (42a) assigns pronouns (represented here as Ds) a particular form (represented here by $/ \mathrm{d} /$ ) according to their feature make-up. All these forms are independent phonological words, as indicated by the $\omega$-subscript. The more specific weakening rule in (42b) assigns an alternative realization to the pronominal DP, a realization which does not consist of a phonological word, but instead is a syllable or a smaller prosodic unit. Thus, the effect of the two rules is one of reduction when a head and a DP are prosodically close, parallel to modern Dutch agreement weakening in the second person singular discussed in section 3.

In the case at hand, reduction involves the phonological form of the pronoun, rather than the non-spell-out of a syntactic feature. Note, however, that the reduction in question cannot be derived by a purely phonological (post-interface) rule, since in several cases there is no plausible phonological relation between the full pronoun and the associated clitic. For example, the object pronoun for the third person feminine singular is haer (/ha:r/), whereas the clitic is se (/sø/).

In contrast to the special spell-out rule discussed in section 3, it appears that the rule in (42b) only applies optionally, since full pronouns can occur in precisely the same position as clitics (see $(39 a, b))$. This may seem awkward at first glance. Since (42b) and the general rule in (42a) stand in 
an elsewhere relation, (42a) should always be blocked in environments where (42b) can apply. However, a special rule can only block a more general one if all else is equal. In particular, the competing derivations must result in identical interpretations. This is probably not the case with the rules in (42). Only if the pronoun is realized as a full prosodic word can it bear stress. Consequently, interpretations that rely on the presence of stress (such as focus or contrastive topic; see Reinhart 1997, Szendroi 2000) can only obtain if the general rather than the special rule applies. In other words, we can maintain that application of the special rule does in fact block application of the general rule, but only if the targeted interpretation is compatible with both resulting structures. The pronouns in $(39 \mathrm{a}, \mathrm{b})$ should hence have a discourse status which differs from that of the clitics in (37). Although likely, this is obviously hard to test for a dead language.

As will be obvious, the prosodic account of Middle Dutch object cliticization avoids the problems with the condition on extraction domains mentioned in connection with the syntactic alternative. It also explains why cliticization to $\mathrm{C}$ consistently involves encliticization. Given that Middle Dutch is a verb second language, XPs in general, and so pronouns as well, can be fronted to a position preceding $\mathrm{C}$ in main clauses (as in (43a)). However, pronouns cannot reduce to clitics if fronted to this position, since they do not find themselves in the same prosodic domain as the verb in C. In other words, the structural description for the weakening rule in (42b) is not met in (43b) (with DP the pronoun).

$$
\begin{array}{ll}
\text { a. } & {\left[{ }_{\mathrm{CP}} \mathrm{DP}\left[{ }_{\mathrm{C}} \mathrm{V}\right]\left[_{\mathrm{IIP}} \text { SUBJECT } \ldots\left[{ }_{\mathrm{vp}} \ldots \mathrm{t}_{\mathrm{DP}} \mathrm{t}_{\mathrm{V}}\right] \ldots\right]\right]} \\
\text { b. } & \{/ \mathrm{dp} /\}\{/ \mathrm{v} / / \text { subject } /\}\{\ldots\}
\end{array}
$$

Let us now compare the situation in modern Dutch with the Middle Dutch state of affairs. Modern Dutch has lost object cliticization to C:

$$
\begin{aligned}
& { }^{*} \text { dat-' } \mathrm{t} \text { Jan gedaan heeft } \\
& \text { that-it John done has }
\end{aligned}
$$

This can be explained in terms of the analysis above. Modern Dutch differs from Middle Dutch in that object pronouns cannot be shifted across the subject any longer. ${ }^{9}$ This is illustrated in (45) (compare with the Middle Dutch examples in (39)).
a. $\quad$ *Toen vroeg hem Lancelot waar de jonkvrouw was then asked him Lancelot where the lady was
b. $\quad *$ dat mij de ziekte zal doen dwalen that me the illness will make wander
c. Toen vroeg Lancelot hem waar de jonkvrouw was then asked Lancelot him where the lady was
d. dat de ziekte mij zal doen dwalen that the illness me will make wander

Given the absence of this type of movement, object pronouns never immediately follow C. Consequently, the structural description of a rule like (42b) is never met; only the representations 
in $\left(41 b, b^{\prime}\right)$ and (41c,c') exist. Hence, such a rule and the specific clitic forms it mentions cannot be acquired in modern Dutch. The language only has strong and weak object pronouns (see Cardinaletti \& Starke 1999 for discussion of the distinction between weak pronouns and clitics).

In fact, the analysis predicts that one type of pronoun can still be cliticized onto $\mathrm{C}$ in modern Dutch. Subject pronouns are usually realized in the same prosodic phrase as the complementizer or the fronted verb (DP in (46) represents the subject pronoun):

$$
\begin{array}{ll}
\text { a. } & {\left[{ } _ { \mathrm { CP } } \ldots \mathrm { C } \left[_{\mathrm{IP}} \mathrm{DP} \ldots\right.\right.} \\
\text { b. } & \{\ldots\}\{\mathrm{c} \mathrm{dp}\}\{\ldots
\end{array}
$$

In (46b), the subject pronoun could undergo a special spell-out rule of the type under discussion. Modern Dutch does indeed have one special clitic form, namely for third person singular masculine subjects. This is the form ie (pronounced /i:/), the clitic counterpart of the full form hij (pronounced /hei/). The following spell-out rules are thus part of modern Dutch grammar:

$$
\begin{array}{ll}
\text { a. } & \Pi([\mathrm{D}, \mathrm{MASC}])=/ \text { hei }_{\omega} / \\
\mathrm{b} . & \text { Modern Dutch Hij Weakening } \\
& \text { In }[\varphi[([\mathrm{V}]), \Pi([\mathrm{D}, \text { MASC }]), \\
& \Pi([\mathrm{D}, \mathrm{MASC}]) \rightarrow / \mathrm{i}_{\sigma} /
\end{array}
$$

If $i e$ is not just a weak pronoun but a clitic form that results from application of (47b) it should behave on a par with the Middle Dutch object clitics. Indeed it does: in all contexts where the subject is not right-adjacent to $\mathrm{C}$, ie cannot appear. This is the case when a constituent is fronted to a position between $C$ and the subject, as in $\left(48 \mathrm{c}, \mathrm{c}^{\prime}\right)$, as well as when the subject is topicalized in a main clause, as in $\left.\left(48 \mathrm{~d}, \mathrm{~d}^{\prime}\right)\right):^{10}$

$$
\begin{aligned}
& \text { a. } \quad \text { dat hij }\} \text { gisteren }\} \text { de afwas }\} \text { deed } \\
& \text { that he } \text { STRONG }_{\text {yesterday the dishes did }} \\
& \text { a' } \quad\{\text { dat ie }\} \text { gisteren }\{\text { de afwas }\} \text { deed } \\
& \text { that he } \text { CL }_{\text {yesterday the dishes did }} \\
& \text { b. } \quad \text { Gisteren }\} \text { deed hij\} \{de afwas\} } \\
& \text { yesterday did he } e_{\text {STRONG }} \text { the dishes } \\
& \text { b'. } \quad \text { Gisteren }\} \text { deed ie }\} \text { de afwas } \\
& \text { yesterday did he } C_{C} \text { the dishes } \\
& \text { c. } \quad\{\text { dat gisteren }\} \text { hij\} }\{\text { de afwas }\} \text { deed } \\
& \text { that yesterday he } \text { STRONG }_{\text {the dishes did }} \\
& \text { c'. } \quad *\{\text { dat gisteren }\} \text { ie }\} \text { de afwas }\} \text { deed } \\
& \text { that yesterday he } e_{C L} \text { the dishes did } \\
& \text { d. } \quad\{\text { Hij }\} \text { \{deed gisteren }\} \text { de afwas } \\
& \text { he } \text { STRONG }_{\text {did }} \text { yesterday the afwas } \\
& \text { d'. } \quad *\{\text { Ie }\} \text { deed gisteren }\} \text { de afwas } \\
& h_{C L} \text { did yesterday the dishes }
\end{aligned}
$$


We find, then, that the occurrence of cliticization depends on whether or not the syntax allows a pronoun to immediately follow a particular head. This confirms the view that this type of cliticization is conditioned by prosodic phrasing.

The proposed analysis seems to predict that object cliticization could occur in specific circumstances in Modern Dutch after all. It is possible for the object to end up to the immediate right of a fronted verb when the subject is topicalized, as in (49).

$$
\begin{aligned}
& \text { a. [CP SUBJECT [C V] [ir } \left.\left.\mathrm{t}_{\text {SUBjeCt }}\left[{ }_{\mathrm{VP}} \mathrm{DP} \mathrm{t}_{\mathrm{V}}\right]\right]\right] \\
& \text { b. }\{/ \text { subject } /\}\{/ \mathrm{v} / / \mathrm{dp} /\}
\end{aligned}
$$

Still, there are no special reduced (clitic) forms of object pronouns that are inserted in this context. The following data illustrate this: ${ }^{11}$

$$
\begin{aligned}
& \text { a. } \quad\{\text { Bob }\} \text { vvergeet haar\} \{nooit\} } \\
& \text { Bob forgets her } \text { STRONG }_{\text {never }} \\
& \text { b. } \quad\{\text { Bob }\} \text { vergeet d'r }\} \text { nnooit\} } \\
& \text { Bob forgets her } r_{W E A K} \text { never } \\
& \text { c. } *\{\text { Bob }\} \text { \{vergeet ze }\} \text { nnooit } \\
& \text { Bob forgets her }{ }_{C L} \text { never }
\end{aligned}
$$

Note, however, that in the syntactic representation of these sentences there is an element between the verb and the object, namely the trace of the subject (see (49a)). Since this trace is an XP, strict application of the prosodic mapping rule in (3) will yield the prosodic representation in (51) rather than (49b). (For the purposes of this paper, we do not assume that traces are present in the phonological representation; their influence is restricted to the triggering of $\varphi$-closure).

$$
\{/ \text { subject } /\}\{/ \mathrm{v} /\}\{/ \mathrm{dp} /\}
$$

In this representation the object pronoun and the fronted verb are not in the same prosodic phrase, so the structural description for a hypothetical special spell-out rule in modern Dutch is not met.

It is not uncommon for phrasal traces to block reduction rules, such as wanna contraction in English (cf. Chomsky 1981). If it is assumed that such reduction rules are conditioned by prosodic phrasing as well, the impossibility of pronoun reduction in (50c) and the ungrammaticality of wanna contraction in (52b) can be explained in the same way. ${ }^{12}$

$$
\begin{aligned}
& \text { a. [Who do [you want [to meet } \left.\left.\mathrm{t}_{\mathrm{WH}}\right]\right] \\
& \text { a'. }\{\text { Who }\} \text { do you }\} \text { want to meet } \\
& \text { a”. } \quad\{\text { Who }\} \text { do you }\} \text { wwanna meet } \\
& \text { b. [Who do [you want [ } \mathrm{t}_{\mathrm{wh}} \text { to meet John]]] } \\
& \text { b'. }\{\text { Who }\} \text { do you }\} \text { want }\} \text { to meet John } \\
& \text { b". * } * \text { Who }\} \text { do you }\} \text { wan }\} \text { nna meet John }
\end{aligned}
$$


Thus, the presence of the subject trace blocks application of an object pronoun reduction rule. This does not mean that a prosodic structure as in (51) (and (52b)) will surface as such. As argued in section 4, there are phonological conditions that apply beyond the PF interface and these deal with weight distribution and balancing effects, amongst other things. It is generally assumed that a phonological phrase which contains less material that some critical measure $\mathrm{M}$ is not well-formed:

$$
*_{\varphi} \text { if } \varphi<M
$$

Suppose that $\mathrm{M}$ is more than a single phonological word (this is too simplistic, but will suffice for the point we want to illustrate). Then, a $\varphi$ consisting of just the realization of a syntactic head will be in danger of violating (53). To avoid ungrammaticality, the material in the offending phrase is adjoined to a preceding or following $\varphi$ (a process that may be compared to stray syllable adjunction at the foot level and stray consonant adjunction at the syllable level). ${ }^{13}$ This results in representations of a type argued for in Truckenbrodt 1999, as in (54), which gives the result of adapting (51) in the way described:

$$
\{/ \text { subject } /\}\{/ \mathrm{v} /\{/ \mathrm{dp} /\}\}\{\ldots\}
$$

Note that even if (54) were generated at PF (rather than in phonology proper), the structural description for pronoun reduction would not be met, since a $\varphi$-boundary separates (the realization of) V and DP. A similar line of argumentation can be applied to the prosodic structure of English wanna contraction.

Prosodic adjunction structures of this type are also expected in OV languages whose prosodic phrasing abides by the alignment condition in (3). This condition forces a representation in which preverbal object and verb form distinct $\varphi$ s, but a $\varphi$ only containing the verb is illformed by (53). Hence, phonology delivers the structure in (55).

$$
\begin{aligned}
& \text { \{dat Jan\} \{ }\{\text { een boek }\} \text { leest }\} \\
& \text { that John a book reads }
\end{aligned}
$$

In (55), too, the structural description for pronoun reduction does not obtain. This means that, as assumed throughout, it does indeed follow from the prosodic mapping principles alone where special spell-out rules can apply. In particular, the order of XP and head does not have to be stated explicitly. In the languages under discussion prosodic phrasing is sensitive to right XP boundaries. Hence, special spell-out rules are correctly restricted to environments in which the XP is rightadjacent, rather than left-adjacent, to the head. ${ }^{14}$

\section{CELTiC Pro Drop}

The above account of object cliticization in Middle Dutch suggests an analysis of pro drop in some Celtic languages which is very much in the spirit of Anderson (1982) and Doron (1988). Consider Irish. The most striking property of this language from the perspective in this paper is that the agreement morphology that is present in pro drop structures (resulting in the so-called synthetic form of the verb) is omitted when the subject is overtly realized (resulting in the so-called analytic 
form of the verb). In this respect, Irish differs from classic pro drop languages like Italian, in which agreement is always present. The examples in (56), from McCloskey \& Hale 1984, illustrate the phenomenon.
a. Chuirfinn isteach ar an phost sin
put-COND-1sg in on that job
'I would apply for that job'
a'. $\quad *$ Chuirfinn mé isteach ar an phost sin
put-COND-1 $\mathrm{sg}$ I in on that job
b. $\quad *$ Chuirfeadh isteach ar an phost sin
put-COND in on that job
b'. Chuirfeadh Eoghan isteach ar an phost sin
put-COND Owen in on that job

Several analyses of the complementary distribution in (56) assume that the apparent agreement ending in (56a) is in fact an incorporated subject pronoun. ${ }^{15}$ There are two basic variants of this view. In one it is assumed that the pronoun is incorporated through syntactic head-to-head movement; the other assumes a phonological or morphological reanalysis.

The syntactic approach faces a couple of problems, one of which it shares with the syntactic analysis of object cliticization in Middle Dutch. First, the condition on extraction domains excludes incorporation out of subject DPs. Second, as pointed out by McCloskey \& Hale (1984), the pronoun can be incorporated from the lefthand part of a coordinated subject, as illustrated in (57). If the incorporation involved syntactic movement, this would violate the coordinate structure constraint.

$$
\begin{aligned}
& \text { da mbeinn-se agus tusa ann } \\
& \text { if be-COND-1 } \mathrm{sg} \text {-CONTR and you-CONTR there } \\
& \text { 'if I and you were there' }
\end{aligned}
$$

The alternative relies on either phonological or morphological adjustment of the verb-pronoun sequence (Doron 1988, Adger 1997). Evidently, the type of special spell-out rule proposed here can provide an account of the data along such lines. The analysis runs entirely parallel to that of Dutch clitics in the previous section.

Note first that the VSO ordering of the Celtic languages has the consequence that verb and subject are realized in the same prosodic phrase. Assuming that VSO word order is derived by verb movement to a functional head F, the following structures obtain (see also section 5 on Arabic):

$$
\begin{aligned}
& \text { a. }\left[{ }_{\mathrm{FP}}[\mathrm{F} \mathrm{V}]\left[{ }_{\text {IP }} \text { SUBJECT } \mathrm{t}_{\mathrm{V}}\left[\mathrm{VP}_{\mathrm{VP}} \mathrm{t}_{\mathrm{V}} \text { OBJECT }\right]\right]\right. \\
& \text { b. } \\
& \{/ \mathrm{v} / / \text { subject } /\}\{/ \text { object } /\}
\end{aligned}
$$

Since the verb and the subject are in the same $\varphi$ in (58b), they can be subject to a special spell-out rule of the format in (6b), with the domain specified as the prosodic phrase. What accounts for the data in (56) then are the rules below: 


$$
\begin{array}{ll}
\text { a. } & \Pi([\mathrm{D},(\mathrm{PRT}),(\mathrm{ADD}), \ldots])=/ \mathrm{d}_{\omega} / \\
\mathrm{b} . & \text { Irish Pronoun Weakening } \\
& \mathrm{In}[\varphi \mathrm{\varphi}([\mathrm{V}]), \Pi([\mathrm{D},(\mathrm{PRT}),(\mathrm{ADD}), \ldots]), \\
& \Pi([\mathrm{D},(\mathrm{PRT}),(\mathrm{ADD}), \ldots]) \rightarrow / \mathrm{d}_{\sigma} /
\end{array}
$$

A feature in which Irish pronoun weakening differs from its Middle Dutch counterpart is that the rule seems to apply obligatorily. As Doron (1988:203) notes: "when a synthetic form exists, such as chuirfinn, it is in general ungrammatical to use an analytic form together with a pronominal subject." This is illustrated by Doron's example in (60) (compare with (56b')).

$$
\begin{aligned}
& { }^{*} \text { Chuirfeadh mé isteach ar an phost sin } \\
& \text { put-COND I in on that job }
\end{aligned}
$$

For Middle Dutch we noted that the optionality of cliticization was only apparent. The full pronoun can only occur in the position fitting the structural description of the weakening rule if it is in focus or a contrastive topic. These interpretations require stress on the pronoun, which is incompatible with realization as a clitic. In Irish, however, an alternative means of marking contrastiveness is employed, namely insertion of the suffix se. This suffix is compatible with full as well as reduced pronouns; the latter option is demonstrated in (61). The existence of this way of marking contrastiveness has the consequence that interpretational requirements cannot block application of the pronoun weakening rule. Due to it being a more specific rule than the general spell-out rule for pronouns, it applies obligatorily whenever its structural description is met.

$$
\begin{aligned}
& \text { Chuirfinn-se } \\
& \text { put-COND-1sg-CONTR }
\end{aligned}
$$

The availability of a special suffix marking contrastiveness in Irish but not Dutch also explains another difference between pronoun weakening in the two languages. Whereas Irish allows reduction of the first part of a coordinated subject only, as was illustrated by (57), the same is impossible in Dutch:
a. dat hij en Jan naar huis gaan
that he STRONG $_{\text {and John to home go }}$
b. $\quad *$ dat ie en Jan naar huis gaan
that he $c_{C L}$ and John to home go

Note that, as such, the phenomenon of first conjunct reduction finds a natural explanation on our account. The alignment condition in (3) has the effect that the verb and the subject's first conjunct form a prosodic phrase from which the second conjunct is excluded:

$$
\begin{array}{ll}
\text { a. } & {\left[{ }_{\mathrm{FP}}[\mathrm{F}\right.} \\
\mathrm{F} & \left.\left.\mathrm{IIP}[\mathrm{DP} \& \mathrm{DP}] \mathrm{t}_{\mathrm{V}}\left[{ }_{\mathrm{VP}} \mathrm{t}_{\mathrm{V}} \ldots\right]\right]\right] \\
\text { b. } & \{/ \mathrm{v} / / \mathrm{dp} /\}\{/ \& / / \mathrm{dp} /\}\{\ldots\}
\end{array}
$$


Hence, the weakening rule may affect the first, but not the second, conjunct.

The reason why this nevertheless does not occur in Dutch is that coordinated pronouns are typically interpreted as being contrastive (cf. Cardinaletti \& Starke 1999). Consequently, destressed forms like clitics or weak pronouns cannot be coordinated in languages that mark contrastiveness by stress, see (64). The coordinated pronoun in the first conjunct of (62) can therefore not undergo reduction to $i e$.
a. $\quad$ Ik zie hem en haar
I see HIM STRONG $_{\text {and }}$ an $r_{\text {STRONG }}$
b. $\quad *$ Ik zie 'm en d'r
I see HIM ${ }_{W E A K}$ and her ${ }_{W E A K}$

Use of the constrastive -se suffix in Irish, which is compatible with reduced forms, avoids this problem. There is no difficulty in weakening a coordinated pronoun as long as -se is present. Indeed, omission of -se results in ungrammaticality; compare (65) with (57):

$$
\begin{aligned}
& \text { *da mbeinn agus tu(sa) ann } \\
& \text { if be-COND-1 } \mathrm{sg} \text { and you(-CONTR) there } \\
& \text { if I and you were there' }
\end{aligned}
$$

As was the case for Dutch, our theory predicts that pronoun weakening is blocked if the pronoun precedes the verb, since in that case pronoun and verb are not in the same $\varphi$. Thus it is no coincidence that the type of agreement alternation discussed is typical of languages whose syntax allows or requires VSO structures (such as Irish, Hebrew (in past and future tenses) and Chamorro). ${ }^{16}$

The relation between VS order and pronoun weakening is corroborated more directly by Welsh. Welsh shows the same alternation between synthetic and analytic forms of the verb as does Irish, but in Welsh it seems to be optionally possible to have a pronoun accompany a synthetic verb form, as in (66).

$$
\begin{aligned}
& \text { 'r oeddwn (i) 'n cwyno } \\
& \text { COMP be-PAST-1.sg (I) in complain } \\
& \text { 'I was complaining' }
\end{aligned}
$$

We assume that the spell-out rules for pronouns in both languages are essentially the same: in postverbal subject position a pronoun undergoes weakening, and obligatorily so. The only difference between the two is that, as argued by Doron, the constrastive marker is spelled out as -se in Irish, while it takes the form of a reduplicant pronoun in Welsh. A parallel type of doubling can be observed with object pronouns in French, cf. Kayne 2000. Unfocussed pronouns are obligatorily cliticized to the verb (by syntactic cliticization in Romance, see section 6). When in focus, however, a tonic double appears in object position. In Kayne's account the clitic and its double start out as one complex DP (see also Uriagereka 1995 and Papangeli 2000 for accounts of clitic doubling in 
other languages based on different variants of this idea). Subsequently, the tonic pronoun is stranded by movement of the clitic, as in (67a).
a. Je [vp [v le vois] [DP $\mathrm{t}_{\mathrm{D}}[\mathrm{DP}$ lui] $\left.]\right]$
I him see him
b. $\quad *$ Je [vp vois [DP luil]
I see him

Note that doubling is obligatory in these contexts, as (67b) shows. This implies that the tonic form is not simply a full counterpart of the clitic, but indeed a double that accompanies the clitic in instances of focus, as assumed for Welsh.

A syntactic difference between Welsh and Irish is that next to VSO order, Welsh also allows fronting of the subject, yielding SVO order. If a verb is combined with a pronominal subject in this order, the pronoun cannot undergo weakening and the verb must appear in its analytic form, see (68). Moreover, if the pronoun is focussed, there is overt doubling; that is, two instances of the pronoun. Thus, this confirms that the synthetic form of the verb is the result of a spell-out rule of the type in (59b), which cannot apply if the pronoun precedes the verb.

$$
\begin{aligned}
& \text { yfi oedd }\left({ }^{*} \text { wn }\right) \text { yn cwyno } \\
& \text { I-REDUP be-PAST }(-1 \text { sg }) \text { in complain }
\end{aligned}
$$

'It was I that was complaining'

We have now seen two processes of pronoun weakening conditioned by prosodic phrasing. In the next section, we discuss a radical variant of this process. Old French pronouns can be reduced to zero in exactly the predicted context.

\section{OLD FRENCH PRO-DROP}

The distribution of pro drop in Old French, as discussed by Adams (1987), displays curious asymmetries between root and embedded clauses and between inverted and non-inverted structures. Old French is a verb second language. Pro drop turns out to be possible in exactly one context, namely in main clauses in which subject-verb inversion would occur if the subject were overt (an observation that goes back to Foulet 1928). Thus, it is possible in declarative main clauses in which a constituent other than the subject is fronted and in yes/no questions, but it is unattested in embedded clauses and subject-initial declaratives; see (69) ((69a,b) are from Adams 1987, (69c,d) are constructed examples of unattested structures).

(69) a. Einsi corurent _ par mer tant que il vindrent à Cademelée thus ran-3plr by sea until they came-3plr to Cadmée

b. Oserai _ le vous demander? dare-1 1 sg it you ask

'Do I dare ask it of you?'

c. *Einsi corurent li Grieu par mer tant que _ vindrent à Cademelée thus ran-3plr the Greeks by sea until came-3plr to Cadmée 
d. *_ corurent einsi par mer tant que il vindrent à Cademelée ran-3plr thus by sea until they came-3plr to Cadmée

The generalization emerging from these data is that omitted subjects must immediately follow the inflected verb. Such a right-adjacency condition is accommodated naturally by the prosodic theory of reduction developed above. Only if the subject immediately follows the inflected verb is it realized in the same prosodic phrase as this head:

$$
\begin{aligned}
& \text { a. [CP (XP) [C V-AGR] [ip SUBJECT } \left.\left.\ldots \text { [VP } \mathrm{t}_{\mathrm{V}} \ldots . . . .\right]\right] \\
& \text { a'. } \quad(\{/ \mathrm{xp} /\})\{/ \text { v-agr/ } / \text { subject } /\}\{\ldots \\
& \text { b. } \quad\left[{ } _ { \mathrm { CP } } \mathrm { C } \left[{ }_{\text {IP }} \text { SUBJECT } \ldots . .{ }_{\mathrm{VP}} \mathrm{V}\right.\right. \text {-AGR ...] ... ]] } \\
& \text { b'. } \quad\{/ \mathrm{c} / / \text { subject } /\}\{\ldots\}\{/ \text { v-agr } / \ldots\}\{\ldots
\end{aligned}
$$

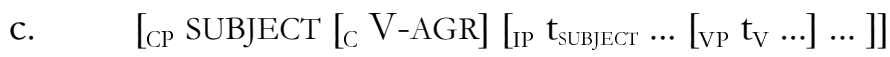

$$
\begin{aligned}
& \text { c'. } \quad\{/ \text { subject } /\}\{/ \text { v-agr/ ... }\}\{\ldots
\end{aligned}
$$

One may therefore assume that this type of pro drop is the result of a context-sensitive spell-out rule, on a par with the reduction rules for pronouns discussed in sections 6 and 7 . There is an important difference, however. The earlier reductions affected the form of the pronoun, rather than the spell-out of its features: the pronoun was realized as a clitic or an affix, but nevertheless all its features were expressed. In contrast, in the Old French case the reduction involves the spell-out of the pronoun's features, since (rather obviously) none of these features is overtly realized in the examples in $(69 \mathrm{a}, \mathrm{b})$. As suggested in section 2 , suppression of features is only possible if identical features occur on the other element in the spell-out rule's local domain. Otherwise, recoverability would not be guaranteed (cf. (9)). The consequence is that Old French pro drop has a more limited distribution than pronoun weakening in Middle Dutch or Celtic. Whereas the latter is possible when the pronoun is right-adjacent to a verbal head, Old French pro drop requires right-adjacency to a head that agrees with the pronoun. This is precisely what the data in (69) show. These data are hence accounted for by the following spell-out rules (for the sake of presentation, we indicate agreement by coindexation of features):

$$
\begin{array}{ll}
\text { a. } & \Pi([\mathrm{D},(\mathrm{PRT}),(\mathrm{ADD}), \ldots])=/ \mathrm{d}_{\omega} / \\
\text { b. } & \text { Old French Pro Drop } \\
& \operatorname{In}\left[\varphi \Pi\left(\left[\mathrm{H},(\mathrm{PRT})_{\mathrm{i}},(\mathrm{ADD})_{\mathrm{j}}, \ldots\right]\right), \Pi\left(\left[\mathrm{D},(\mathrm{PRT})_{\mathrm{i}},(\mathrm{ADD})_{\mathrm{j}}, \ldots\right]\right),\right. \\
& \Pi([\mathrm{D},(\mathrm{PRT}),(\mathrm{ADD}), \ldots]) \rightarrow \Delta
\end{array}
$$

The symbol $\Delta$ introduced by this rule carries the phonetic instruction that it is not to be pronounced.

Old French pro drop is thus analyzed on a par with Dutch second person agreement weakening (see section 3), except that in Old French the pronoun, rather than a feature of the agreeing verb, fails to be spelled out.

As was the case in Middle Dutch, Old French pronoun weakening appears to be optional. But again this is only apparent, since the structure with the overt pronoun and the structure with the reduced (null) pronoun fulfill different discourse functions. According to Sprouse \& Vance 
(1999:274) "null and overt pronouns in postverbal position, although they are referentially equivalent, carry the potential for a discourse distinction that is realized in declaratives". In particular, covert postverbal subject pronouns are associated with thematic (old) information in spec-CP, whereas overt pronouns can be associated with new information in this position (Vance 1997). Moreover, Adams (1987:6, fn.6) notes that Old French also did not have a series of special tonic forms of the pronouns, but used one series for both nonemphatic and emphatic contexts. This means that, as assumed for Middle Dutch (but, again, hard to test for a dead language), the overt post-V subject pronouns may also have been emphatic, a reading obviously incompatible with the null form.

As in the earlier cases, it is imaginable that a syntactic condition requires adjacency to a head for pro drop to occur. This is, in fact, what Adams (1987) proposes. She analyzes Old French pro drop as involving an empty pronominal subject pro. Following Rizzi (1986), she assumes that the occurrence of pro is subject to two conditions: both its content and its position must be identified. The general consensus seems to be that content identification of pro relies on rich agreement, which Old French has. Adams further argues that positional identification of pro is done by head government in a particular direction. This is summed up in (72) (Adams's (8)).

(72) a. The position and content of pro must be identified

i. The position of pro is identified by a governing head

ii. The content of pro is identified by coindexation with the proper features

b. Government of pro (a.i) must be in the canonical direction.

On the further assumptions that the governing head mentioned in (72a.i) is $\mathrm{I}^{0}$, and that this head governs to the right (Old French is a VO language), the data in (69) follow.

Again, however, it seems to us that the prosodic account has advantages over an account in syntactic terms, in this case government. Apart from the fact that the syntactic account does not extend to the other cases unified under the prosodic account, some of the properties of the phenomenon at hand are quite unexpected. First of all, the licensing conditions in (72) must crucially involve the surface position of pro. In subject-initial declarative main clauses, a trace of the subject is governed in the canonical direction by the inflected verb, see (73a). It is unclear why this is not sufficient to license a fronted pro. Other properties of nominal elements that require government in GB theory, such as case licensing of object DPs, can be licensed by government of a trace of the element in question, see (73b).

$$
\begin{aligned}
& \text { a. } \quad *\left[\mathrm{cp} p r o[\mathrm{C} \mathrm{V}-\mathrm{AGR}]\left[\mathrm{IP}_{\mathrm{ip}} \mathrm{t}_{\text {pro }} \ldots\left[\mathrm{VVP}_{\mathrm{VP}} \mathrm{t}_{\mathrm{V}} \ldots\right] \ldots\right]\right] \\
& \text { b. [CP DP-ACC [C V-AGR] [ip SUBJECT ... [ [vp } \left.\left.t_{\mathrm{V}} \mathrm{t}_{\mathrm{DP}} \ldots . . .\right]\right]
\end{aligned}
$$

In contrast, a PF account does explain why it is the surface position of the element to be reduced that counts.

Moreover, in the syntactic account it is accidental that it is I that must govern pro. After all, there is no reason why the licenser of pro's content (which undoubtedly is I) and the licenser of its position should be one and the same. In fact, this is denied by Rizzi (1986) in his account of Italian object pro. It must hence be stipulated in the syntactic account that government by $\mathrm{C}$ is not sufficient 
for positional licensing of pro (government by $\mathrm{C}$ would license the ungrammatical $(65 \mathrm{c})$ ). In the end, then, the syntactic account of the ungrammaticality of pro drop in embedded clauses in Old French is based on a stipulation. As argued, the prosodic account explains why right-adjacency to an agreeing head (rather than to an arbitrary head) is expected in cases of non-spell-out.

\section{ARABIC PRO DROP}

In section 5 we discussed the phenomenon of agreement weakening in VSO structures in Standard Arabic. As it turns out, Arabic has a second prosodically conditioned reduction rule, which targets the subject rather than the verb. This second rule is identical to the rule of pro drop in Old French, proposed in the previous section. Pronominal subjects can fail to be spelled out if they follow an agreeing head, a situation captured by the following two spell-out rules (identical to those in (71)):

$$
\begin{array}{ll}
\text { a. } & \Pi([\mathrm{D},(\mathrm{PRT}),(\mathrm{ADD}), \ldots])=/ \mathrm{d}_{\omega} / \\
\text { b. } & \text { Arabic Pro Drop } \\
& \operatorname{In}\left[\varphi \Pi\left(\left[\mathrm{H},(\mathrm{PRT})_{\mathrm{i}},(\mathrm{ADD})_{\mathrm{j}}, \ldots\right]\right), \Pi\left(\left[\mathrm{D},(\mathrm{PRT})_{\mathrm{i}},(\mathrm{ADD})_{\mathrm{j}}, \ldots\right]\right),\right. \\
& \Pi([\mathrm{D},(\mathrm{PRT}),(\mathrm{ADD}), \ldots]) \rightarrow \Delta
\end{array}
$$

The specific rule in (74b) can, and therefore must, apply in VSO structures like (75a,a') (assuming the subject is not focussed or a contrastive topic); SVO structures like (75b,b') only allow application of the general rule in $(74 a)$.

$$
\begin{aligned}
& \text { a. [FP [F V] [ip SUBJECT } t_{\mathrm{V}}\left[{ }_{\mathrm{VP}} \mathrm{t}_{\mathrm{V}}\right. \text { OBJECT]]] } \\
& \text { a'. } \quad\{/ \mathrm{v} / / \text { subject } /\}\{\text { /object/ }\} \\
& \text { b. [FP SUBJECT [F V] [ip } \mathrm{t}_{\text {SUBJECT }} \mathrm{t}_{\mathrm{V}}\left[{ }_{\mathrm{V}} \mathrm{t}_{\mathrm{V}}\right. \text { OBJECT]]] } \\
& \text { b'. }\{/ \text { subject } /\}\{/ \mathrm{v} / / \text { object } /\}
\end{aligned}
$$

At first sight, it would seem difficult to prove that only postverbal subjects undergo pro drop. Omission of the subject in both SVO and VSO structures results in a surface VO string. Moreover, since pro drop is only possible if there is full agreement on the verb, and full agreement is typical precisely of SVO order (see section 5), one might be inclined to draw the opposite conclusion, namely that pro drop is restricted to preverbal subjects. However, there is what seems to be conclusive empirical evidence for postverbal, and against preverbal, pro drop. The data involve clauses introduced by one of two complementizers, the first of which exclusively shows up in VSO clauses, while the second requires SVO order.

The complementizer Panna assigns accusative case to a subject to its right under adjacency. Hence, it only occurs in SVO clauses (Fassi Fehri 1993):

(76) a. Tanna n-nisaa?-an daxal-na makaatib-a-hunna that the-women-ACC entered-FEM-PLR office-PLR-ACC-their-FEM

b. $\quad *$ ?anna daxal-at n-nisaa?-u / n-nisaa?-an makaatib-a-hunna that entered-FEM the-women-NOM / the-women-ACC office-PLR-ACC-their-FEM 
Now, as noted by Mohammad (1991:100) "the complementizer Panna 'that' never allows pro to follow it". Mohammad provides the following data in support:

(77) a. al-?awlaad-u qaaluu ?anna-hum saafaruu the-boys-NOM said-3PLR-MASC that-they departed-3PLR-MASC

b. *al-?awlaad-u qaaluu ?anna _ saafaruu the-boys-NOM said-3PLR-MASC that departed-3PLR-MASC

This shows that pro drop is impossible in preverbal position.

The second complementizer is ?an, which does not have case assigning properties and perhaps as a result of this does not license SVO order (Fassi Fehri 1993). VSO order is obligatory, as (78) shows.

(78) a. $\quad *$ ?an n-nisaa ?-u / n-nisaa ?-an daxal-at makaatib-a-hunna that the-women-NOM / the women-ACC entered-FEM office-PLR-ACC-their-FEM

b. ?an daxal-at n-nisaa?-u makaatib-a-hunna that entered-FEM the-women-NOM office-PLR-ACC-their-FEM

As observed by Plunkett (1994:236), pro drop is licensed in these structures. She gives the example below in evidence:

$$
\begin{aligned}
& \text { y-uriid-u ?an ya-xruju-a } \\
& \text { want-3.M.SG that leave-3-MASC-SG-SUBJ }
\end{aligned}
$$

This shows that pro drop is possible in postverbal position, in accordance with the rule in (74b).

As noted, subject omission in Arabic does not only bear on the theory of pro drop, but also on accounts of strong versus weak agreement. The reason is that we unexpectedly find obligatory strong agreement in pro drop structures, which, as we have just seen, have a postverbal subject (cf. (80)). (In contrast, VSO structures with an overt subject show weak agreement, see section 5).

$$
\begin{aligned}
& \text { ya-dxul-uuna _ al bayt-a } \\
& \text { enter-3.MASC.PLR the house-ACC }
\end{aligned}
$$

It seems hard to account for this observation in the minimalist syntactic analysis of Arabic agreement sketched in section 5 . Recall that in this account, strong agreement triggers overt raising of the subject to the specifier of an agreement projection, while weak agreement is only checked after spell-out (covertly). Hence, given that pro drop must be licensed by strong agreement, it should be restricted to preverbal position. Put differently, if strong agreement must be checked in overt syntax, it is hard to see how lack of phonological content in the subject would void this requirement.

In contrast, the prosodic approach provides a natural account of the difference in agreement in VSO clauses with and without pro drop. Both pro drop and weak agreement are the result of reduction rules, which affect the subject and the verb respectively. The question raised by the obligatory strong agreement in pro drop structures, then, is why application of the pro drop rule 
would block application of the agreement weakening rule. Why can both reduction rules not apply at the same time?

The reason is that application of agreement weakening and omission of the subject in the same structure violates recoverability, which was argued in section 2 to subsume (81).

A triggering feature cannot be suppressed

As noted above, special spell-out rules can suppress the realization of a particular feature if an identical feature (the 'triggering feature' in (81)) is present on the other element in the local prosodic domain. Here, we have two such rules. Agreement weakening suppresses the phonological realization of the plural feature on the verb, which is triggered by an identical feature on the subject. Pro drop, which is triggered by phi-features on the verb, suppresses realization of all phi-features of the subject, including its plural feature. If both rules were to trigger each other, the condition in (81) would be violated. ${ }^{17}$

To conclude this section, let us return to an issue left open in section 5 . Whereas overt postverbal lexical DP subjects trigger agreement weakening, overt postverbal pronominals do not. This is demonstrated by the following example from Aoun et al. (1994:209):
a. Naamuu hum
slept-MASC-PLR they
b. *Naama hum
slept-MASC-SG they

Given the above discussion of pro drop in Arabic, this fact can now be analyzed on a par with the co-occurrence of synthetic verb forms with an overt pronominal subject in Welsh and the cooccurrence of object clitics with tonic pronominal doubles in French. Following Doron (1988), we have assumed that (apparent) pro drop in Welsh is in fact obligatory: postverbal subject pronouns are always reduced to phonological affixes. However, when the subject is focussed, the reduced pronoun is doubled by a full form (cf. (83a,a')). Similarly, emphasis is reconciled with object cliticization in French by a tonic pronominal double (cf. (83b)).

$$
\begin{array}{ll}
\text { a. } & {\left[\mathrm{FP} V\left[\text { [P }\left[\left[\text { PRONOUN }_{1}\right] \text { PRONOUN }_{2}\right] \ldots\right]\right]} \\
\text { a'. } & \left\{/ \text { vaffix }_{1} / / \text { pronoun }_{2} /\right\}\{\ldots \\
\text { b. } & \text { Je [ } \left.[\text { VP [V le vois }]\left[\mathrm{DP}_{\mathrm{D}}[\mathrm{DP} \text { lui }]\right]\right]
\end{array}
$$

The same pattern is found in Arabic. Pro drop is obligatory. However, if the subject is focussed, it is doubled by a tonic pronoun (see also Benmamoun 1997; for discussion of pronoun doubling in general in Arabic, see the papers in Eid 1996). Since pro drop blocks weakening of verbal agreement, as we have just seen, the structure will require strong agreement:

$$
\begin{aligned}
& \text { a. } \left.\quad\left[\text { FP V-AGR }\left[\text { IP }\left[\text { pronoun }_{1}\right] \text { pronoun }_{2}\right] \ldots\right]\right] \\
& \text { b. } \quad\left\{/ \text { v-agr } / \Delta / \text { pronoun }_{2} /\right\}\{\ldots
\end{aligned}
$$


This concludes our discussion of reduction rules triggered by the presence of identical syntactic features. In the next section we discuss checking in prosodic domains, an option implied by the existence of context-sensitive spell-out rules..

\section{GERMANIC COMPLEMENTIZER AGREEMENT}

Many of the rules discussed so far suppress realization of a feature on an element when a second element with identical specification for that feature is near. This implies that PF must be able to detect the presence of identical features on distinct elements within a local domain. But such detection is in fact a well-known phenomenon in syntactic theory, often referred to as checking. Certain features are licensed only when checked locally. It is expected, then, that feature checking can take place at PF, with the checking domain specified as the prosodic phrase. This is expressed by the general rule in (85), where FB stands for some feature bundle, for example A and B's phifeatures.

$$
\begin{aligned}
& \text { In }\left[{ } _ { D } \Pi \left(\left[\left[_{A} \ldots F B \ldots\right]\right), \Pi\left(\left[\left[_{B} \ldots F B \ldots\right]\right)\right]\right.\right. \text {, } \\
& \text { where } F B \subseteq\left\{F_{1}, F_{2}, F_{3}, \ldots\right\},
\end{aligned}
$$

$\mathrm{FB}$ is checked

In this section we argue that the phenomenon of complementizer agreement in certain Germanic languages constitutes a case of PF checking.

As an initial illustration of the phenomenon, consider the following West-Flemish data. The subject in Flemish agrees with the complementizer in person and number (see Haegeman 1992, De Schutter 1997 and Shlonsky 1994). The paradigm for complementizer agreement is exemplified in (86). It is identical in form to the verbal agreement paradigm; differences in surface form result from independently motivated phonological adjustments. ${ }^{18}$

$\begin{array}{ll}\text { (86) } & \text { dan ik werken } \\ & \text { that-1SG I work-1SG } \\ \text { b. } & \text { da gie werkt } \\ & \text { that-2SG you work-2SG } \\ \text { da ze/Valère werkt } & \text { that-3SG she/Valère work-3SG } \\ \text { c. } \quad \text { dan wunder werken } \\ \text { that-1PL we work-1PL } \\ \text { da gunder werkt } \\ \text { that-2PL you-PL work-2PL } \\ \text { dan zunder/Pol en Valère werken } \\ \text { that-3PL they/Pol and Valère work-3PL }\end{array}$

Since various instances of agreement have been analyzed in terms of checking in syntax, one option would be to extend this account to complementizer agreement. The obvious problem is that the structural configuration in which syntactic checking is assumed to take place is that between a head and its specifier. In the case of complementizer agreement, this configuration does not obtain, at 
least not at an observational level. The constituent with which the complementizer agrees is embedded in its complement. It is in fact even impossible to move the subject to spec-CP:

*... wunder dan $t$ werken

... we that-1PL work-1PL

The observation that at least on the surface complementizer agreement does not require a specifierhead relationship can be strengthened by looking at East-Netherlandic dialects, as discussed by Van Haeringen (1958). In these dialects, as opposed to what we find in Flemish, the regular verbal agreement and complementizer agreement have different paradigms. This is illustrated below:
a. datte wij speult
that-PL we play-PL
a'. $\quad *$ datte wij speule
that-PL we play-PL
b. Wij speult
we play-PL
b'. *Wij speule
we play-PL
c. $\quad *$ Dan speult wij
then play-PL we
c'. Dan speule wij
then play-PL we

There are two plural endings, $-e$ and $-t$, which have a different distribution. The - $t$ appears whenever there is a spec-head configuration between the subject and the agreeing element. If there is no such configuration, $-e$ is used. Thus, the ending involved in complementizer agreement, $-e$, cannot be used on the verb if the subject precedes it, only if it follows it (on the surface).

These data can be reconciled with approaches based on uniform checking in specifier-head configurations by assuming that such a configuration obtains at an earlier stage of the derivation. In particular, one could assume an agreement projection below $\mathrm{C}$, whose head checks the subject's features and subsequently moves to adjoin to C:

$$
\left.\left.\left[\mathrm{CP} \text { C-Agr [AgrP DP [Agr, } \mathrm{t}_{\mathrm{Agr}} \cdots\right]\right]\right]
$$

Such proposals come in two variants in the literature. In one, the agreement projection is the projection in which regular subject-verb agreement is also checked, say AgrSP (cf. Zwart 1997a). In the other it is a special AgrC phrase in the COMP domain of the clause (cf. Shlonsky 1994). Both these syntactic approaches face serious problems, however.

First, the syntactic distribution of the subject, verb and other material in the Germanic OV languages can be accounted for without the agreement phrase in question. The empirical evidence for its existence is hence indirect at best (see section 3 for some discussion). There is no compelling conceptual argument for agreement phrases either, since the concept 'agreement' by definition refers 
to a relation rather than a particular semantic notion which could be expressed by a head (cf. Chomsky 1995, chapter 4). Hence, to assume such projections only to reconcile the data in (86) and (88) with the assumption that checking uniformly requires a specifier-head configuration is not very attractive.

A second problem with analyses of the type in (89) is that complementizer agreement is retained if the AGR-head moves into the C-projection, but not if the subject does so. In the latter case, we find regular verbal agreement, as demonstrated by the East-Netherlandic data in (88). If checking in intermediate stages of the derivation is allowed, this asymmetry is unexpected. One way to deal with this problem is to adopt the asymmetric theory of Verb Second (Travis 1984, Zwart1997a). Recall from section 3 that according to this theory, subject-initial root clauses are IPs (or more precisely AgrSPs), while nonsubject-initial clauses are CPs. If so, the type of agreement can be linked to the type of head in which it occurs. The data in (88) can be understood if plural agreement is spelled out as $-t$ in I (or AgrS) and V, and as $-e$ in C:

$$
\begin{aligned}
& \text { a. [CP datte [AgrSP wij [Agrs, AgrS [vp ... speult]]]] } \\
& \text { that-PL we play-PL } \\
& \text { b. } \quad[\text { agrS Wij }[\text { agr' }[\text { agrs } \text { speult }] \ldots]] \\
& \text { we play-PL } \\
& \text { c. } \quad\left[\mathrm { CP } \text { Dan } \left[{ } _ { C } [ { } _ { C } \text { speule } ] \left[{ } _ { \mathrm { AgrSP } } \text { wij } \left[{ }_{\mathrm{ArgS}}, \mathrm{AgrS}\right.\right.\right.\right. \text {...]]] } \\
& \text { then play-PL we }
\end{aligned}
$$

However, as pointed out before, the asymmetric theory of Verb Second incorporates as one option the traditional analysis involving topicalization to spec-CP. Since there is no principled reason why the subject could not be topicalized, (88b'), with the structure in (91), cannot be ruled out.

$$
\begin{aligned}
& { }^{*}\left[_ { \mathrm { CP } } \mathrm { Wij } \left[\mathrm{C},\left[\mathrm { C } \text { speule] } \left[{ } _ { \mathrm { AgrSP } } \mathrm { t } _ { \mathrm { DP } } \left[{ }_{\mathrm{Args}}, \mathrm{AgrS}\right.\right.\right. \text {...]]]] }\right.\right. \\
& \text { we play-PL }
\end{aligned}
$$

The third problem for analyses based on Agr projections is that complementizer agreement and verbal agreement sometimes co-occur, while they are in complementary distribution elsewhere. In (86) and (88a), both the complementizer and the verb carry agreement, which would seem to be incompatible with the analysis in which a single AgrS phrase is assumed to be the locus of checking for both types of agreement. But assuming two Agr heads, as in Shlonsky's theory, leads to another problem, namely why only one agreement ending shows up on fronted verbs (cf. (88b-c)). The examples below are ungrammatical:
a. $\quad *$ Wij speul-t-e
we play-PL-PL
b. $\quad *$ Dan speul-t-e wij
then play-PL-PL we

Shlonsky (1994:366-367) does account for this fact, but at the cost of introducing auxiliary assumptions that do not follow from the syntactic checking theory as such. 
Finally, it seems to be the case that complementizer agreement requires the agreeing head and the subject to be adjacent in surface structure. This can be shown in idiolects of Flemish in which complementizer agreement is optional. Here, when $\mathrm{C}$ appears in its agreeing form, it cannot be separated from the subject by adverbials or other fronted material. This restriction is lifted, however, when $\mathrm{C}$ appears without an agreement ending (examples from Peter Vermeulen, personal communication; see also Haeberli 1999:184):

(93) a. da / dan zunder op den warmste dag van 't jaar tegen under wil gewerkt en that / that-3PLR they on the hottest day of the year against their will worked have

b. $\quad \mathrm{da} / *$ dan op den warmste dag van 't jaar zunder tegen under wil gewerkt en that / that-3PLR on the hottest day of the year they against their will worked have

Again it is not impossible to account for these data in an approach based on checking in specifierhead configurations. Shlonsky, for example, gives an account based on conditions on nominative case assignment and a prohibition against adjunction of adverbials in the COMP domain. But again, the existence of these conditions, and hence of the adjacency restriction, does not follow from the core assumptions of the general approach of syntactic agreement checking.

By contrast, complementizer agreement shows the hallmarks of a prosodically conditioned process. It does not occur when the agreeing head and the subject fail to be adjacent ((93b) versus (93a)), and it does not occur when the subject precedes the head ((88b) versus $\left.\left(88 c^{\prime}\right)\right)$. Therefore, we believe that complementizer agreement is a particular instance of the general PF feature checking rule in (85), with D specified as the prosodic phrase:

$$
\begin{aligned}
& \text { Germanic C Agreement Checking } \\
& \text { In }\left[\varphi \Pi\left(\left[{ }_{C} \ldots \mathrm{FB} \ldots\right]\right), \Pi\left(\left[\left[_{\mathrm{DP}} \ldots \mathrm{FB} \ldots\right]\right)\right]\right. \text {, } \\
& \text { where } \mathrm{FB} \subseteq\{\text { PRT, ADD, PLR }\}, \\
& \text { FB is checked }
\end{aligned}
$$

To be sure, this rule is not meant to replace the presumably universal option of feature checking in syntax. It is simply an additional way of checking features made available by the hypothesis that PF operations can be context-sensitive in the relevant way.

The rule in (94) explains why complementizer agreement requires adjacency of the C-head and the subject, as illustrated for Flemish in (93). The syntactic and prosodic structures of these examples are given in (95). Since the subject does not form a prosodic phrase with C in (95b'), the rule in (94) is not applicable. As argued above, the configuration for syntactic checking also does not obtain, so that the complementizer must appear in its non-agreeing form. In (95a') the structural description of the rule $i s$ met and hence insertion of an agreeing complementizer is licensed.

$$
\begin{aligned}
& \text { a. } \quad\left[\text { Cр } \mathrm{C}\left[\text { Ip SUBJECT } \ldots\left[\mathrm{vp}_{\mathrm{vp}} \mathrm{V} \ldots\right] \ldots\right]\right. \\
& \text { a'. } \quad\{/ \mathrm{c} / / \text { subject } /\}\{\ldots\}\{/ \mathrm{v} / \ldots\}\{\ldots \\
& \text { b. [CP } \mathrm{C}[\text { IP XP [IP SUBJECT ... [VP } \mathrm{V} \text {...] ... ]] } \\
& \text { b'. } \quad\{/ \mathrm{c} / / \mathrm{xp} /\}\{/ \text { subject } /\}\{\ldots\}\{/ \mathrm{v} / \ldots\}\{\ldots
\end{aligned}
$$


Notice that the co-occurrence of complementizer agreement and verbal agreement is unproblematic, given that the subject can form a prosodic phrase with $\mathrm{C}$ at $\mathrm{PF}$ while occupying a position triggering verbal agreement in syntax. This accounts for (86), with agreement on both the complementizer and the verb. Note also that in root clauses with subject-verb inversion agreement can be checked both syntactically and prosodically:

$$
\begin{array}{ll}
\text { a. } & {\left[\mathrm{CP} \mathrm{XP}[\mathrm{C} \mathrm{V}]\left[{ }_{\mathrm{IP}} \operatorname{SUBJECT} \ldots\left[\mathrm{vP} \ldots \mathrm{t}_{\mathrm{V}} \ldots\right] \ldots \mathrm{t}_{\mathrm{V}} \ldots\right]\right]} \\
\text { b. } & \{/ \mathrm{xp} /\}\{/ \mathrm{v} / / \text { subject } /\}\{\ldots
\end{array}
$$

Given the option of syntactic checking in this configuration the subject need no longer be adjacent to $\mathrm{C}$ even though it agrees with it. This prediction is borne out (Peter Vermeulen, personal communication):

Volgens Valère en op den warmste dag van 't jaar zunder tegen under wil gewerkt. according to Vakère have-3PLR on the hottest day of the year they against their will worked

The rule in (94) is sufficient to account for the distribution of complementizer agreement in Flemish. The actual form of the agreement is regulated by a set of general spell-out rules for verbal heads (verbs and complementizers). However, not only can $\mathrm{C}$ agreement be checked in prosodic domains, it can also be subject to context-sensitive spell-out. Indeed, the East-Netherlandic dialects precisely differ from Flemish in having such a special spell-out rule for plural agreement, (98b), next to the general rule in $(98 \mathrm{a}) .{ }^{19}$

$$
\begin{aligned}
& \text { a. } \quad \Pi([\text { Head } V, \text { PLR ...] }])=/ \text { head } /-/ t / \\
& \text { b. } \quad \text { In }[\varphi \varphi([\text { head } \ldots \text { V, Plr ...] }), \Pi([\ldots \text { D, Plr ...] })] \\
& \Pi([\text { Head } \ldots . . V, \text { PlR ...] }) \rightarrow / \text { head/-/e/ }
\end{aligned}
$$

Note that these rules stand in an elsewhere relation: (98b) is more specific than (98a). This implies that when both can be applied (that is, when the subject immediately follows the agreeing head), (98b) takes precedence over (98a). It follows, then, that in root clauses with subject-verb inversion, agreement will be realized as /-e/ rather than /-t/ (or /-t/ plus /-e/; see (92b)).

Of course, (98a) will be applied in the absence of post-head adjacency, so in contexts that necessarily require syntactic agreement checking, as in (99). Indeed, we saw that when the subject precedes the agreeing head, plurality is realized as /-t/.

$$
\begin{array}{ll}
\text { a. } & {\left[\text { CP SUBJECT }\left[\mathrm{C} \text { V] [IP } \mathrm{t}_{\text {SUBßECT }} \ldots\left[\mathrm{vvp}_{\mathrm{V}} \mathrm{t}_{\mathrm{V}} \ldots\right] \ldots\right]\right]} \\
\text { b. } & \{/ \text { subject } /\}\{/ \mathrm{v} / \ldots\}\{\ldots
\end{array}
$$

Interestingly, if we are correct then the same should hold when the subject does follow the head but is not adjacent to it, as in the structures in (100).

(100) a. [CP ... [C V] [IP XP [IP SUBJECT ... [ [vp t ...] ... ]]

$$
\text { b. } \quad\{\ldots\}\{/ \mathrm{v} / / \mathrm{xp} /\}\{/ \text { subject } /\}\{\ldots\}\{/ \mathrm{v} / \ldots\}\{\ldots
$$


It turns out that the agreement form used in structures like (100) is indeed the general, not the special, one, as can be shown on the basis of the Hellendoorn dialect (Jan Nijen Twilhaar, personal communication). This dialect shows the by now familar alternation between the regular $-t$ ending and complementizer agreement in -e:

(101) a. Wiej loopt noar 't park we walk-PL to the park

b. darre wiej noar 't park loopt that-PL we to the park walk-PL

d. Volgens miej lope wiej noar 't park according-to me walk-PL we to the park

If a constituent is fronted to a position between the verb and a postverbal subject, only the regular agreement form can be used:

Volgens miej loopt/*lope op den wärmsten dag van 't joar ook wiej noar 't park according-to me walk-pl/ walk-pl on the hottest day of the year also we to the park.

Note that these data provide direct counterevidence against the idea that it is the syntactic position of the verb that determines the form of its agreement, since this position is not different in (102) as compared to cases of inversion in which subject and verb happen to be adjacent.

\section{CONCLUSION}

The type of rule proposed in this paper bears some similarity to the stylistic rules of Rochemont (1978). Like Rochemont, we claim (i) that there is a set of rules that 'adjust' what is delivered by the syntax on a language-particular basis and (ii) that these rules are located on the grammar's left-hand side: they do not feed semantic interpretation. We have argued that such rules have two main advantages: they allow an overall simplification of the grammar and they make it possible to generalize over a set of phenomena that have received non-uniform treatments in the literature.

As opposed to Rochemont's stylistic rules, the rules we propose are not an addition to the grammar. We have argued, following Halle \& Marantz (1993) and Jackendoff (1997), that syntax and phonology are independent generative systems related by mapping procedures. Since mapping must involve the alignment of syntactic and phonological domains as well as the phonological realization of syntactic terminals, the system implies the option of context-sensitive spell-out. If an element is realized in the same prosodic domain as a particular other element, it may be spelled out in a different way than when it does not. Being implied by the notion of PF mapping, context-sensitive spell-out does not constitute a qualitative extension of the theory.

Although they are language-specific, the context-sensitive spell-out rules we have proposed share certain crucial properties. They all refer to the prosodic phrase, with the effect that a uniform description becomes available of an at first sight disparate set of morphosyntactic adjustments (including agreement weakening, pro drop and complementizer agreement). Moreover, there are limitations on what the rules can do. Most rules involve reduction. If the reduction does not involve features shared by affected element and trigger, it may only involve phonological form. If the 
reduction does involve shared features, it is subject to recoverability. So, although context-sensitive spell-out is language-specific (like all spell-out rules), there are universal conditions on the context it applies in and the output it delivers.

We have formulated the various context-sensitive spell-out rules we have proposed in a theory-neutral fashion, namely as rules mentioning a context, an input and an output (cf. Chomsky $\&$ Halle 1968). However, what the rules express is not tied to this particular format. We conclude the paper with a brief illustration of how suppression of features can be dealt with in optimality theory, the framework currently dominant in phonology (Prince \& Smolensky 1993). One advantage of such a reformulation is that it reduces the amount of language-specificity of the proposed rules to the ordering of universal constraints, while the effects of the elsewhere principle follow from minimal constraint violation, both core notions in optimality theory.

The situation we want explore is the one expressed by the rules in (103). According to these rules a head $\mathrm{H}$ containing features $\mathrm{F}_{1}$ and $\mathrm{F}_{2}$ is spelled out as $/ \mathrm{h} /$, unless it is realized in the same prosodic phrase as an XP bearing $\mathrm{F}_{2}$. In that case, the effects of $\mathrm{F}_{2}$ on $\mathrm{H}$ are suppressed, so that its phonological realization will be $/ \mathrm{h} /$. Note that it is the elsewhere principle that decides which rule applies in which context.

$$
\begin{aligned}
& \text { (103) a. } \quad \Pi\left(\left[\begin{array}{llll}
{\left[_{\mathrm{H}}\right.} & \ldots & \mathrm{F}_{1} & \ldots
\end{array}\right]\right)=/ \mathrm{h} / \\
& \text { b. } \quad \Pi\left(\left[{ }_{\mathrm{H}} \ldots \mathrm{F}_{1}, \mathrm{~F}_{2} \ldots\right]\right)=/ \mathrm{h}^{\prime} / \\
& \text { c. } \operatorname{In}\left[\varphi\left[\left(\left[_{\mathrm{H}} \ldots \mathrm{F}_{1}, \mathrm{~F}_{2} \ldots\right]\right), \Pi\left(\left[\mathrm{xp} \ldots \mathrm{F}_{2} \ldots\right]\right)\right]\right. \text {, } \\
& \Pi\left(\left[_{\mathrm{H}} \ldots \mathrm{F}_{1}, \mathrm{~F}_{2} \ldots\right]\right) \rightarrow \Pi\left(\left[\mathrm{H} \ldots \mathrm{F}_{1} \ldots\right]\right)
\end{aligned}
$$

In another language the situation in which $\mathrm{F}_{2}$ is spelled out twice in the same prosodic domain may be avoided by suppressing its effects for the phonological realization of XP (cf. (104)). Yet another language may not have suppression of $\mathrm{F}_{2}$ in either $\mathrm{H}$ or XP (such a language would lack both (103c) and $(104 \mathrm{c}))$.

$$
\begin{array}{ll}
\text { a. } & \Pi\left(\left[\mathrm{xp} \ldots \mathrm{F}_{3} \ldots\right]\right)=/ \mathrm{xp} / \\
\text { b. } & \Pi\left(\left[\mathrm{xp} \ldots \mathrm{F}_{2}, \mathrm{~F}_{3} \ldots\right]\right)=/ \mathrm{xp} / \\
\text { c. } & \operatorname{In}\left[\varphi \left(\Pi \left(\left[\begin{array}{l}
{[\mathrm{H}} \\
\end{array}\right.\right.\right.\right. \\
& \left.\Pi\left(\left[\mathrm{F}_{2} \ldots\right]\right), \Pi\left(\left[\mathrm{xp} \ldots \mathrm{F}_{2}, \mathrm{~F}_{3}, \ldots\right]\right)\right], \\
&
\end{array}
$$

The rules in (103c) and (104c) can be reanalyzed in terms of three constraints. The first is a constraint, akin to the OCP, that is violated if two agreeing features are realized in the same prosodic phrase (assuming the local domain $\mathrm{D}$ is specified as such):

$$
\begin{aligned}
& \text { No local duplicate features (NLDF) } \\
& *\left\{\Pi\left(\mathrm{F}_{\mathrm{i}}\right), \Pi\left(\mathrm{F}_{\mathrm{i}}\right)\right\}
\end{aligned}
$$

The other two constraints require that all features of an element are parsed in phonology. As will become clear as we proceed, there should be separate constraints stating this for $\mathrm{H}$ and XP: 
(106) a. Parse $H$

Parse all features of $\mathrm{H}$

b. Parse XP

Parse all features of XP

Suppose that both XP and $\mathrm{H}_{\text {carry }} \mathrm{F}_{2}$ in syntax and that XP immediately follows $\mathrm{H}$. If the constraints are ranked as in (107), the optimal candidate will be the one in which $\mathrm{F}_{2}$ on $\mathrm{H}$ fails to be realized:

\begin{tabular}{|l|l|l|l|}
\hline$\left[\ldots\left[\mathrm{H} \mathrm{F}_{1} \mathrm{~F}_{2}\right]\left[\mathrm{xp} \mathrm{F}_{2} \mathrm{~F}_{3}\right] \ldots\right]$ & NLDF & Realize XP & Realize $\mathrm{H}$ \\
\hline$\left\{/ \mathrm{h}^{\prime} / / \mathrm{xp} /\right\}$ & $* !$ & & \\
\hline$\{/ \mathrm{h} / / \mathrm{xp} /\}$ & & & $*$ \\
\hline$\{/ \mathrm{h} / / \mathrm{xp} /\}$ & & $* !$ & \\
\hline$\{/ \mathrm{h} / / \mathrm{xp} /\}$ & & $* !$ & $*$ \\
\hline
\end{tabular}

If $\mathrm{H}$ and XP appear in any other context, (105) does not come into play, with the consequence that all H's features must be realized. This is illustrated by the tableau in (108), in which XP precedes $\mathrm{H}$.

(108)

\begin{tabular}{|l|l|l|l|}
\hline$\left[\ldots\left[\mathrm{xp} \mathrm{F}_{2} \mathrm{~F}_{3}\right]\left[\mathrm{H}_{1} \mathrm{~F}_{2}\right] \ldots\right]$ & NLDF & Realize XP & Realize $\mathrm{H}$ \\
\hline$\{/ \mathrm{xp}, /\}\left\{/ \mathrm{h}^{\prime} / \ldots\right.$ & & & \\
\hline$\{/ \mathrm{xp} /\}\{/ \mathrm{h} / \ldots$ & & & $* !$ \\
\hline$\{/ \mathrm{xp} /\}\{/ \mathrm{h} / \ldots$ & $* !$ & \\
\hline
\end{tabular}

In other words, this ranking derives the effects of (103c). The effects of (104c) are derived by reversing the order of the parse constraints. In that case, the optimal output if XP follows $\mathrm{H}$ will be the one in which $\mathrm{F}_{2}$ on XP is reduced:

\begin{tabular}{|l|l|l|l|}
\hline$\left[\ldots\left[\mathrm{H} \mathrm{F}_{1} \mathrm{~F}_{2}\right]\left[\mathrm{xp} \mathrm{F}_{2} \mathrm{~F}_{3}\right] \ldots\right]$ & NLDF & Realize $\mathrm{H}$ & Realize XP \\
\hline$\{/ \mathrm{h} / / \mathrm{xp} /\}$ & $* !$ & & \\
\hline$\{/ \mathrm{h} / / \mathrm{xp} /\}$ & & $* !$ & \\
\hline \multirow{2}{*}{$/ \mathrm{h} / / \mathrm{xp} /$} & & & $*$ \\
\hline$\{/ \mathrm{h} / / \mathrm{xp} /\}$ & & $* !$ & $*$ \\
\hline
\end{tabular}


Finally, if the two parse constraints dominate (105), a language results in which $F_{2}$ is never suppressed:

(110)

\begin{tabular}{|l|l|l|l|}
\hline$\left[\ldots\left[\mathrm{H} \mathrm{F}_{1} \mathrm{~F}_{2}\right]\left[\mathrm{xP}_{2} \mathrm{~F}_{3}\right] \ldots\right]$ & Realize $\mathrm{H}$ & Realize XP & NLDF \\
\hline$\left\{/ \mathrm{h}^{\prime} / / \mathrm{xp} /\right\}$ & & & $*$ \\
\hline$\{/ \mathrm{h} / / \mathrm{xp} /\}$ & $* !$ & & \\
\hline$\left\{/ \mathrm{h}^{\prime} / / \mathrm{xp} /\right\}$ & & $* !$ & \\
\hline$\{/ \mathrm{h} / / \mathrm{xp} /\}$ & $* !$ & $*$ & \\
\hline
\end{tabular}

Note that suppression of the identical feature on both H and XP is suboptimal on any ranking. Hence, this candidate is ruled out universally, as required (compare the situation in Arabic, section 9). A deconstruction of the other rules we have proposed along similar lines should be possible.

To conclude, we have argued that a number of morphological alternations which are conditioned by adjacency should not be analyzed syntactically but rather as involving rules operating at the syntax-phonology interface. This does not constitute a qualitative extension of theoretical machinery, since the notions referred to by such rules are independently motivated. In fact, it makes available a unified account of phenomena which require unrelated auxiliary hypotheses if dealt with in syntax proper. Thus, the paper provides another argument for modularity in grammar. 


\section{REFERENCES}

Adams, Marianne: 1987, 'From Old French to the Theory of Pro-Drop', Natural Language and Linguistic Theory 5, 1-32.

Adger, David: 1997, 'VSO Clause Structure and the Morphological Elimination of Strong Categorial Features', Ms., University of York.

Anderson, Stephen: 1982. 'Where’s Morphology?’, Linguistic Inquiry 13, 571-612.

Aoun, Joseph, Elabbas Benmamoun and Dominique Sportiche: 1994, 'Agreement, Word Order, and Conjunction in Some Varieties of Arabic', Linguistic Inquiry 25: 195-220.

Baker, Mark: 1988, Incorporation, University of Chicago Press, Chicago.

Benmamoun, Elabbas: 1996, 'Agreement Asymmetries and the PF Interface', SOAS Working Papers in Linguistics 6: 106-128.

Benmamoun, Elabbas: 2000, The Feature Structure of Functional Categories, Oxford University Press, Oxford.

Besten, Hans den: 1983, 'On the Interaction of Root Transformations and Lexical Deletive Rules', in W. Abraham (ed.) On the Formal Syntax of the West-Germania, John Benjamins, Amsterdam, pp. 47-131.

Brame, Michael: 1976, 'Alternatives to the Tensed S and Specified Subject Conditions', Linguistics and Philosophy 1, 381-411.

Büring, Daniel: 2000, 'Let's Phrase It!', Ms., University of California, Santa Cruz.

Cardinaletti, Anna, and Ian Roberts: 1991, 'Clause Structure and X-Second', Ms., University of Venice and University of Geneva.

Cardinaletti, Anna, and Michal Starke: 1999, 'The Typology of Structural Deficiency', in H. van Riemsdijk (ed.) Clitics in the Languages of Europe, Mouton de Gruyter, Berlin, pp. 145-233.

Chomsky, Noam: 1981, Lectures on Government and Binding, Foris, Dordrecht.

Chomsky, Noam: 1995, The Minimalist Program, MIT Press, Cambridge.

Corver, Norbert, and Denis Delfitto: 1993, 'Feature Asymmetry and the Nature of Pronoun Movement', Ms., Tilburg University and Utrecht University.

Doron, Edit: 1988, 'On the Complementarity of Subject and Subject-Verb Agreement', in M. Barlow and C. Fergusson (eds.) Agreement in Natural Language: Approaches, Theory, Description, CSLI Publications, Stanford, pp. 201-218.

Eid, Mushira (ed.): 1996, Perspectives on Arabic Linguistics VI, John Benjamins, Amsterdam.

Fassi Fehri, Abdelkader: 1989, 'Generalized IP Structure, Case, and VS Order', MIT Working Papers in Linguistics 10, 75-111.

Fassi Fehri, Abdelkader: 1993, Issues in the Structure of Arabic Clauses and Words, Kluwer, Dordrecht.

Fodor, Janet Dean: 2001, Prosodic Disambiguation in Silent Reading, Paper presented at Prosody in Processing, Utrecht University.

Foulet, Lucien: 1928, Petite syntaxe de l'ancien français, Champion, Paris.

George, Leland: 1980, Analogical Generalizations of Natural Language Syntax, Ph.D. dissertation, MIT.

Gestel, Frank van, Jan Nijen Twilhaar, Tineke Rinkel and Fred Weerman: 1992, Oude zinnen, Martinus Nijhoff, Leiden.

Grimshaw, Jane: 1991, 'Extended Projection', Ms., Brandeis University.

Haan, Germen de: 1997, 'Voegwoordcongruentie in het Fries', in E. Hoekstra and C. Smits (eds.) Vervoegde voegwoorden, Edita, Amsterdam, pp 50-67. 
Haan, Germen de, and Fred Weerman: 1986, 'Finiteness and Verb Fronting in Frisian', in H. Haider and M. Prinzhorn (eds.) Verb Second Phenomena in Germanic Languages, Foris, Dordrecht, pp. $77-110$.

Haeberli, Eric: 1999, Features, Categories and the Syntax of A-Positions, Ph.D. dissertation, University of Geneva.

Haegeman, Liliane: 1990, 'Subject Pronouns and Subject Clitics in West-Flemish', The Linguistic Review 7: 333-363.

Haegeman, Liliane: 1992, Theory and Description in Generative Syntax: A Case Study in West Flemish, Cambridge University Press, Cambridge.

Haeringen, C.B. van: 1958, 'Vervoegde voegwoorden in het Oosten', in C.B. van Haeringen (ed.) Gramarie, Van Gorkum, Assen, pp. 309-318.

Halle, Morris, and Alec Marantz: 1993, 'Distributed Morphology and the Pieces of Inflection', in K. Hale and S.J. Keyser (eds.) The View from Building 20, MIT Press, Cambridge, pp. 111-176.

Harley, Heidi, and Elizabeth Ritter: 1998, 'Meaning in Morphology: Motivating a Feature-Geometric Analysis of Person and Number', Ms., University of Pennsylvania and University of Calgary. Hoeksema, Jacob: 1985, 'Wazdat: Contracted Forms and Verb Second in Dutch', in J.T. Faarlund (ed.) Germanic Linguistics: Papers from a Symposium at the University of Chicago. BULC, Bloomington, pp.112-124.

Hoekstra, Eric: 1993, 'Minimalist Implications of Inflected Complementisers', Ms., P.J. Meertens Institute, Amsterdam.

Hoekstra, Eric: 1996, 'On the Interaction between Agreement and Pronouns in the 2SG Present Tense in Dutch', Ms., P.J. Meertens Institute, Amsterdam.

Hoekstra, Jarich: 1997, 'Pro-drop, clitisering en voegwoordcongruentie in het Westgermaans', in E. Hoekstra and C. Smits (eds.) Vervoegde voegwoorden, Edita, Amsterdam, pp. 68-86.

Horst, Joop van der: 1981, Kleine Middelnederlandse syntaxis, Huis aan de Drie Grachten, Amsterdam. Huang, James: 1982, Logical Relations in Chinese and the Theory of Grammar, Ph.D. dissertation, MIT. Huybregts, Rini: 1991, 'Allosteric Agreement in VSO Languages', in F. Drijkoningen and A. van Kemenade (eds.) Linguistics in the Netherlands 1991, John Benjamins, Amsterdam, pp. 81-90. Jackendoff, Ray: 1997, The Architecture of the Language Faculty, MIT Press, Cambridge.

Kayne, Richard: 2000, 'A Note on Clitic Doubling in French', Ms., New York University.

Kerstens, Johan: 1993, The Syntax of Number, Person and Gender, Mouton de Gruyter, Berlin.

Leben, William: 1973, Suprasegmental Phonology, Ph.D. dissertation, MIT.

Manzini, Rita, and Anna Roussou: 2000, 'A Minimalist Theory of A-Movement and Control', Lingua 110, 409-447.

McCarthy, John: 1986, 'OCP Effects: Gemination and Anti-Gemination', Linguistic Inquiry 17: 207263.

McCarthy, John, and Alan Prince: 1995, 'Generalized Alignment' in G. Booij and J. van Marle (eds.) Yearbook of Morphology 1994, Kluwer, Dordrecht, pp.@@

McCloskey, James: 1996, 'On the Scope of Verb Movement in Irish', Natural Language and Linguistic Theory 14:47-104.

McCloskey, James, and Kenneth Hale: 1984, 'On the Syntax of Person-Number Inflection in Modern Irish’, Natural Language and Linguistic Theory 1:487-533. 
Menn, Lise, and Brian MacWhinney: 1984, 'The Repeated Morph Constraint: Toward an Explanation', Language 60: 519-541.

Miller, Philip, and Ivan Sag: 1997, 'French Clitic Movement without Clitics or Movement', Natural Language and Linguistic Theory 15: 573-639.

Mohammad, M.A.: 1990, 'The Problem of Subject-Verb Agreement in Arabic: Towards a Solution', in M. Eid (ed.) Perspectives on Arabic Linguistics I, John Benjamins, Amsterdam, pp. 95-125.

Monachesi, Paola: 1999, A Lexical Approach to Italian Clitics, CSLI Publications, Stanford.

Müller, Gereon, and Wolfgang Sternefeld: 1993, 'Improper Movement and Unambiguous Binding', Linguistic Inquiry 24: 461-507.

Muysken, Pieter: 1982, 'Parametrizing the Notion “Head"', Journal of Linguistic Research 2: 57-75.

Paardekooper, Piet: 1961, 'Persoonsvorm en voegwoord', De nieuwe taalgids 54: 296-301.

Papangeli, Dimitra: 2000, 'Clitic Doubling in Modern Greek', UCL Working Papers in Linguistics 12: 473-498.

Plunkett, Bernadette: 1994, 'The Position of Subjects in Modern Standard Arabic', in M.Eid and C. Holes (eds.) Perspectives on Arabic Linguistics V, John Benjamins, Amsterdam.

Prince, Alan, and Paul Smolensky: 1993, Optimality Theory. Ms., Rutgers University and University of Colorado, Boulder.

Reinhart, Tanya: 1995, Interface Strategies, Ms., Utrecht University.

Rizzi, Luigi: 1986, Null Objects in Italian and the Theory of pro', Linguistic Inquiry 17: 501-557.

Rochemont, Michael: 1978, A Theory of Stylistic Rules in English, Garland, New York.

Schutter, Georges de: 1997, 'Incorporatie-in-C in de Vlaamse en Brabantse dialecten' in E. Hoekstra and C. Smits (eds.) Vervoegde voegwoorden, Edita, Amsterdam, pp. 31-49.

Selkirk, Elizabeth: 1986, 'On Derived Domains in Sentence Phonology', Phonology Yearbook 3: 371405.

Shlonsky, Ur: 1994, 'Agreement in Comp', The Linguistic Review 11: 351-375.

Sproat, Richard: 1985, 'Welsh Syntax and VSO Structure', Natural Language and Linguistic Theory 3: 173-216.

Sprouse, Rex, and Barbara Vance: 1999: 'An Explanation for the Decline of Null Pronouns in Certain Germanic and Romance Languages', in M. DeGraff (ed.) Language Creation and Language Change, MIT Press, Cambridge, Mass, pp. 257-284.

Stowell, Timothy: 1981, Origins of Phrase Structure, Ph.D. dissertation, MIT.

Stump, Gregory: 1984, ‘Agreement vs. Incorporation in Breton', Natural Language and Linguistic Theory 2: 289-348.

Szendroi, Kriszta: 2001, Focus and the Syntax-Phonology Interface, Ph.D. dissertation, UCL.

Travis, Lisa: 1984, Parameters and Effects of Word Order V ariation, Ph.D. dissertation, MIT.

Truckenbrodt, Hubert: 1995, Phonological Phrases: Their Relation to Syntax, Focus, and Prominence, Ph.D. dissertation, MIT.

Truckenbrodt, Hubert: 1999, 'On the Relation between Syntactic Phrases and Phonological Phrases', Linguistic Inquiry 30: 219-255.

Uriagereka, Juan: 1995, 'Aspects of the Syntax of Clitic Placement in Western Romance', Linguistic Inquiry 26: 79-123.

Vance, Barbara: 1997, Syntactic Change in Medieval French: Verb Second and Null Subjects, Kluwer, Dordrecht. 
Vikner, Sten, and Bonnie Schwartz: 1996, 'The Verb Always Leaves IP in V2 Clauses', in A. Beletti and L. Rizzi (eds.) Parameters and Functional Heads, Oxford University Press, Oxford.

Weerman, Fred: 1987, 'The Change from OV to VO as a Possible Change', in F. Beukema and P. Coopmans (eds.) Linguistics in the Netherlands 1987, Foris, Dordrecht, pp. 223-232.

Weerman, Fred: 1989, The V2 Conspiracy, Foris, Dordrecht.

Williams, Edwin: 1998, 'Review of Zwart (1997), Journal of Comparative Germanic Linguistics 1: 263-272.

Zwart, Jan-Wouter: 1997, The Morphosyntax of Verb Movement, Kluwer, Dordrecht. 


\section{NOTES}

1. E. Hoekstra (1996) also judges sentences of the type in (17b), where the subject contains a DPinternal modifier, unacceptable (as is the case in Frisian as well, see De Haan 1997 and J. Hoekstra 1997). To us, it seems perfect. We speculate that the idiolect of speakers rejecting (17b) involves an additional operation of phonological word formation of the verb-subject sequence in the relevant context, which would be blocked by the DP-internal modifier. A similar analysis could be developed for Frisian.

2. For the sake of brevity, we will sometimes refer to Modern Standard Arabic as 'Arabic'.

3. Huybregts in fact assumes that there is overt agreement checking in VSO structures as well, the difference with SVO being that there is an empty expletive specified as $3^{\text {rd }}$ singular present in the higher subject position in apparent VSO structures. This assumption also underlies the analyses in Fassi Fehri 1989 and Mohammad 1990. Fassi Fehri (1993:38-42) points out a number of disadvantages of this view, however. Most importantly, it seems to us, is that it just shifts the problem, since the question now is why the empty expletive must be specified as singular while being associated with a plural subject.

4. In line with minimalist assumptions, checking takes place in the functional domain. The subject may have been base-generated in spec-VP, something from which we abstract away in (35). Finally, we assume that the subject moves to the regular subject position, spec-IP, in order to check nominative case, but this, too, is irrelevant for the argument.

5. A possible problem for the approach to the Arabic agreement alternation we propose are VOS orders, in which agreement is weak. This fact cannot be due to a rule of phonological reduction, given that verb and subject are not in the same prosodic domain. One alternative would be to assume that in the case of VOS order no [PL] feature can be generated on the verb. Suppose, for example, that such a feature must be checked in syntax, and that syntactic checking requires the relevant phrase to precede the head (as is standardly assumed in minimalism). This would make a verb bearing [PL] compatible with VSO and SVO sentences (in which the subject precedes the verb or its trace), but incompatible with VOS order. Thus, weak agreement with VOS order would be a case of non-generation rather than reduction. As explained in the main text, an account based on syntactic checking cannot as such be responsible for agreement weakening in VSO contexts.

6. This analysis (or the syntactic analysis in terms of head movement mentioned below) appears to be more appropriate for cliticization of the type found in Romance. In Romance, as opposed to Germanic, clitics move along with the verb and show up in positions from which their pronominal counterparts are barred.

7. This problem can perhaps be avoided by adopting a view on clitics originally proposed by Muysken (1982), according to which they are simultaneously heads and maximal projections. On this view, there is no extraction of a head from an adjunct or specifier when the clitic incorporates. However, the analysis faces another problem. In order for the first movement (to the left edge of IP) not to violate the head movement constraint, a phrasal chain must be formed. Syntactic 
incorporation of phrases into heads is presumably impossible, however, so the second movement step must involve a head chain. The resulting composite chain therefore violates chain uniformity (cf. Chomsky 1995; or, alternatively, the lowest trace violates Müller \& Sternefeld's (1993) principle of unambiguous binding).

8. Unless the subject is a clitic itself. In that case there is still no phi-barrier between the verbal head in $\mathrm{C}$ and the object pronoun, and so we expect it to possibly undergo cliticization, resulting in a post-C subject-object clitic cluster. This is correct, as the following example shows (from Van Gestel et al. 1992:147):

Soe darict $\mathrm{u}$ vertellen wel so dare-I-it you tell well

9. Focused elements or contrastive topics can be fronted to a position preceding the subject (see $\left(17 a^{\prime}\right)$ and (23a) for examples). Object pronouns can undergo this movement as well. This does not affect the argument, however, since reduction of foci and contrastive topics is impossible to begin with, as argued above.

10. Note that the order in $\left(48 \mathrm{c}, \mathrm{c}^{\prime}\right)$ strongly favours focussing of the subject, which precludes the use of a weak pronoun as well. However, if something else in the sentence is focussed, weak pronouns can be used in this order, whereas use of $i e$ still leads to ungrammaticality. An example is given below:

(i) a. dat op mooie dagen ze alleen over reisjes naar het zuiden wil praten

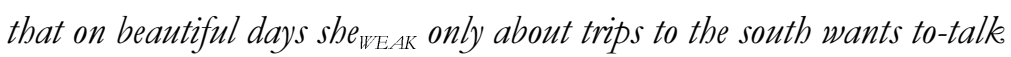

b. $\quad *$ dat op mooie dagen ie alleen over reisjes naar het zuiden wil praten that on beautiful days he $e_{C L}$ only about trips to the south wants to-talk

11. Here we borrow the clitic form ze from Middle Dutch. The same form does in fact still occur in some variants of Dutch today. Strikingly, and as predicted, these dialects still have object cliticization to $\mathrm{C}$ (and pronoun fronting across the subject). An example is West-Flemish, see Haegeman 1990.

12. The argument is based on the assumption that examples like (52a) do not contain a PRO subject (as argued by Brame 1976, Manzini \& Roussou 1999 and others). Alternatively, if there is a PRO subject, it could be assumed to follow VP (not being exceptionally case-marked by the matrix verb).

13. The direction of adjunction (to the preceding or to the following $\varphi$ ) is determined by the direction of recursion imposed by the syntactic head whose realization makes up the offending $\varphi$.

14. Given this reasoning, we expect reduction of object pronouns to clitics to be possible without movement in VO languages. (Note, again, that cliticization of the type found in Romance involves a different process altogether). 
15. Similar data in other Celtic languages have also been assumed to involve pronoun incorporation, see for instance Anderson 1982 on Breton and Adger 1997 on Scottish Gaelic. Stump (1984) provides a critique of Anderson's incorporation analysis. We believe that the more serious of the problems he mentions are problems for the syntactic incorporation analysis only, as discussed below.

16. Or more precisely, VSO structures in which no XP trace intervenes between V and S; cf. section 5 .

17. A condition like this seems to hold of phonological reduction in general. Moira Yip (personal communication) points out the following example. The Obligatory Contour Principle (Leben 1973, McCarthy 1981) triggers degemination. Thus, a string / ...ff.../ may be realized as /...f.../. This, too, is an operation of deletion triggered by the local presence of an identical element. And again it is impossible for the identical elements to trigger each other's deletion, which would give $/ \ldots \varnothing \ldots /$ as output. Mutual reduction is blocked in this case just as it is in Arabic pro drop in VSO structures with strong agreement.

18. Haegeman (1992) suggests that the underlying form of the complementizer marking the second and third person singular, as well as the second person plural, is dat. The -tending is truncated before a consonant and voiced before a vowel. There is some dialect variation in the form of the paradigm as well. In particular, the -en for 1st person singular is omitted by some speakers.

19. The rule in (102b) may in fact be an instance of a reduction rule. It is possible that what the rule really does is reduce the $[+\mathrm{V}]$ feature of the agreeing head, with the result that the plural is spelled out as a general form that also spells out the plural of nominals in the language. According to Hoekstra (1993), special complementizer agreement (as opposed to complementizer agreement which is identical in form to verbal agreement) indeed always has the same shape as a nominal plural marker in the language in question. 